\title{
LINKING HETEROGENEOUS CLIMATE POLICIES (CONSISTENT WITH THE PARIS AGREEMENT)
}

\author{
Michael A. Mehling, ${ }^{*}$ Gilbert E. Metcalf, ${ }^{* *} \&$ Robert N. Stavins ${ }^{* * *}$
}

The Paris Agreement to the United Nations Framework Convention on Climate Change has achieved one of two key necessary conditions for ultimate success - a broad base of participation among the countries of the world. But another key necessary condition has yet to be achievedadequate collective ambition of the individual nationally determined contributions. How can the climate negotiators provide a structure that will include incentives to increase ambition over time? An important part of the answer can be international linkage of regional, national, and subnational policies, that is, formal recognition of emission reductions undertaken in another jurisdiction for the purpose of meeting a Party's own mitigation objectives. A central challenge is how to facilitate such linkage in the context of the very great heterogeneity that characterizes climate policies along five dimensions - type of policy instrument; level of government jurisdiction; status of that jurisdiction under the Paris Agreement; nature of the policy instrument's target; and the nature along several dimensions of each Party's Nationally Determined Contribution. We consider such heterogeneity among policies, and identify which linkages of various combinations of characteristics are feasible; of these, which are most promising; and what accounting mechanisms would make the operation of respective linkages consistent with the Paris Agreement.

\section{INTRODUCTION}

The Paris Agreement, adopted by the Twenty-First Conference of the Parties ("COP-21") of the United Nations Framework Convention on Climate Change ("UNFCCC"), ${ }^{1}$ features a hybrid policy architecture, which combines top-down elements for monitoring, reporting, and verification, with bottom-up elements, including Nationally Determined Contributions ("NDCs") that specify what each country intends to do to reduce its emissions, taking into account domestic political feasibility and other relevant factors. With this architecture, the Agreement represented a dramatic departure from almost two decades of negotiations prior to COP-15 in Copenhagen in 2009, and thereby appeared to achieve a key necessary condition for ultimate success, namely

* Deputy Director, Center for Energy and Environmental Policy Research, Massachusetts Institute of Technology, and Professor, University of Strathclyde School of Law. The authors gratefully acknowledge valuable comments on a previous version of the paper by Susan Biniaz, Daniel Bodansky, Constanze Haug, Christina Hood, and Andrei Marcu; and financial support from the Enel Foundation. The authors, however, are fully responsible for any errors and all opinions expressed in this paper.

** Professor of Economics, Tufts University, Research Associate of the National Bureau of Economic Research, Associate Scholar of the Harvard Environmental Economics Program, and University Fellow of Resources for the Future.

*** A. J. Meyer Professor of Energy and Economic Development, Harvard Kennedy School, Research Associate of the National Bureau of Economic Research, and University Fellow of Resources for the Future.

1 Paris Agreement (Dec. 13, 2015), in UNFCCC, Report of the Conference of the Parties on its Twenty-First Session, Addendum, at 21, FCCC/CP/2015/10/Add.1 (Jan. 29, 2016), https://perma.cc/5ZRS-4NP3 [hereinafter Paris Agreement].

A peer-reviewed, accepted author manuscript of the following research article: Mehling, M. A., Metcalf, G. E., \& Stavins, R. N. (2018). Linking heterogeneous climate policies (consistent with the Paris Agreement). Environmental Law, 48(4). 
adequate scope of participation, with participating nations accounting for approximately $97 \%$ of global greenhouse gas ("GHG") emissions, ${ }^{2}$ in contrast with the Kyoto Protocol (current, second commitment period), which accounts for $14 \%$ of global emissions from participating nations with quantified targets.

The other key necessary condition for ultimate success of this new approach is adequate, collective ambition of the individual NDCs, including net emissions reductions that would put the world on a path toward achieving the global goal of limiting temperature increases to well below 2 degrees Centigrade. A central question is how to provide a structure and/or incentives that will facilitate increases in ambition over time. International linkage of regional, national, and subnational policies can be an important part of the answer.

By linkage, we mean a formal recognition by a GHG mitigation program in one jurisdiction (a regional, national, or sub-national government) of emission reductions undertaken in another jurisdiction for purposes of complying with the first jurisdiction's mitigation policy. ${ }^{3}$ Linkage can be very straightforward, as with the bilateral recognition of allowances under two cap-and-trade regimes, but linkage can also take place among a heterogeneous set of policy instruments, such as between systems of performance standards, carbon taxes, and cap-and-trade.

Leading up to the Paris Agreement, linkage was a core focus of one key track of international climate negotiations, namely the Framework for Various Approaches ("FVA"), which originated at COP-13 in Bali, Indonesia in 2007. ${ }^{4}$ One challenge for negotiators in Paris was to ensure that the Agreement they reached would facilitate the growth and operation of international linkages, and, at a minimum, not put in place inappropriate or excessive rules that would obstruct effective, bottom-up linkage. ${ }^{5}$ This was achieved with Article 6 of the Paris Agreement (Appendix 1), which recognizes that some Parties ${ }^{6}$ to the Agreement "choose to pursue voluntary cooperation in the implementation of their nationally determined contributions" through "the use of internationally transferred mitigation outcomes."7

A challenge now for jurisdictions around the world considering international linkages, as well as for those preparing guidance for the implementation of the Paris Agreement, is the substantial degree of heterogeneity that characterizes climate policies along three dimensions: different types of policy instruments; different levels of political jurisdictions implementing those policies; and different types of targets. Our purpose is to consider such heterogeneity among policies, and identify which linkages of various combinations of characteristics are feasible; of

2 If the United States proceeds to withdraw from the Paris Agreement, as it has announced it will do, the share of global GHG emissions associated with nations participating in the Agreement will fall from $97 \%$ to $82 \%$.

3 Our use of the term linkage should not be confused with the concept of linkage in the international relations literature, where it refers to negotiated agreements between countries in which multiple issues are negotiated and "linked" for purposes of coming to agreement on the overall package. See Ernst Haas, Why Collaborate? IssueLinkage and International Regimes, 32 WORLD POL. 357 (1980).

4 Framework Convention on Climate Change, Bali Action Plan, U.N. Doc. FCCC/CP/2007/6/ADD.1 (March 14, 2008), https://perma.cc/GLB4-WYGP.

5 Daniel M. Bodansky, Seth A. Hoedl, Gilbert E. Metcalf \& Robert N. Stavins, Facilitating Linkage of Climate Policies through the Paris Outcome, 15 ClimATE POL'Y 1 (2015).

6 Parties to the Agreement are individual countries plus the European Union.

7 Neither Article 6 of the Paris Agreement nor the text of the accompanying Decision offers a definition of an Internationally Transferred Mitigation Outcome ("ITMO"), but the International Emissions Trading Association has proposed the following: "An internationally transferred mitigation outcome (ITMO) is the subtraction of a given absolute quantity of greenhouse gas emissions measured in tonnes of carbon dioxide equivalent from the quantitatively defined nationally determined contribution of a given Party ... and the addition of an equivalent amount to the quantitatively defined nationally determined contribution ... of another Party", INTERNATIONAL EMISSIONS TRADING ASSOCIATION, ARTICle 6 OF THE PARIS AgREEMENT IMPLEMENTATION GUIDANCE: AN IETA 'STRAW PROPOSAL' (Nov. 2017), https://perma.cc/UK56-NRUA. 
these, which are most promising; and what accounting mechanisms (under Article 6) would make the operation of respective linkages consistent with the Paris Agreement. Parties to the Agreement are scheduled to adopt the rulebook to implement the Agreement at COP-24 in December 2018.

To be clear, there are thus three conceptually - and operationally - distinct aspects of international policy linkage: (1) provisions in Article 6 of the Paris Agreement and related guidance that can facilitate international linkage, by providing - for example - for Internationally Transferred Mitigation Outcome (ITMOs) to be used as an accounting mechanism when "compliance" with NDCs is measured; (2) agreements between two jurisdictions (Parties to the Paris Agreement or possibly sub-national jurisdictions) to recognize emission reductions generated in the other jurisdiction; and (3) two or more compliance entities, with at least one in each of the linked jurisdictions, engage in an exchange, such as with allowances moving between two capand-trade systems.

The paper is organized as follows. In Section I, we briefly review the arguments for linkage. In Section II, we examine the various options that exist under the major types of policy heterogeneity, relating these to the current status of climate policies around the world and to the actual NDCs submitted under the Paris Agreement. In Section III, we identify five key cases of potential climate policy linkages, and examine each of these from a physical, economic, and legal perspective. Then, in Section IV, we conclude by drawing on our analysis to identify common threads, lessons, policy implications, and pending questions still to be answered.

\section{WHY IS LINKING IMPORTANT?}

The major economic argument for linkage is cost effectiveness, meaning the ability to achieve a given level of emission reductions at the lowest cost to society. Since a major impediment to ambitious climate policy is concern about the economic cost of mitigation, any policy that can lower the cost of mitigation should lower political resistance to ambitious policy. ${ }^{8}$ We explain and demonstrate in Appendix 2 how equalizing the marginal cost of abatement across firms is a necessary condition for a globally cost effective policy.

Linkage provides a mechanism to facilitate a shift of abatement activities from one country to another by allowing firms in the first country to count emission reduction efforts they facilitate in the second country towards meeting their own obligations (in the first country). How this mechanism operates depends on the type of climate policy in effect in each of the linking countries, as we discuss below. ${ }^{9}$

Thus, a major argument for linkage is the aggregate cost savings that linkage can bring about through convergence toward a common price of carbon - whether explicit with carbonpricing instruments or implicit with other policy instruments - in the two linked jurisdictions. It

8 Global cost is certainly not the only impediment to climate policy. Countries care about how that global cost is allocated among countries, and have concerns about how policy may affect future development opportunities. However, those concerns may be more easily addressed as global costs are decreased through the use of costeffective policies. That said, cost-effectiveness in achieving any short-run climate policy goal may not ensure the longer-term energy-sector transformation needed to move to a zero-carbon economy. So, while equalizing marginal abatement costs is a necessary condition for global cost effectiveness, it is not sufficient for achieving all long-term goals.

9 Note that in the case illustrated in Appendix 2, allowance price (in cap-and-trade systems) in Country A fall from $\mathrm{P}_{\mathrm{A}}$ to $\mathrm{P}$, and increase in country $\mathrm{B}$ from $\mathrm{P}_{\mathrm{B}}$ to $\mathrm{P}$. 
has been estimated that international linkage could reduce the cost of achieving the emissions reductions specified in the initial set of NDCs under the Paris Agreement by $32 \%$ by 2030 and by $54 \%$ by $2050 .{ }^{10}$ Another potential merit of linkage is improvement in the functioning of the individual markets through reduced market power and reduced total price volatility, although the link also potentially transmits price volatility from one jurisdiction to another. ${ }^{11}$ Importantly, under the Paris Agreement's structure of voluntary statements of targets by each Party through its NDC, linkage holds promise of providing a means to achieve cost-effectiveness without sacrificing the UNFCCC's principle of common but differentiated responsibilities and respective capabilities. ${ }^{12}$

Linkage also raises legitimate concerns, however, including the distributional impacts that will be felt in each jurisdiction, due to the presence of both winners and losers among individual firms and ultimately among different consumer groups to the extent changes in allowance prices are passed through to final consumers. For example, when allowance prices change (converge) in two linked cap-and-trade systems, firms that are allowance buyers benefit if they are in the system where prices fall, whereas firms that are allowance sellers benefit if they are in the system where prices increase. ${ }^{13} \mathrm{In}$ addition, as we discuss below, linkage can bring about the automatic propagation of some design elements (in particular with cap-and-trade systems, cost-containment mechanisms, such as banking provisions) from one jurisdiction to another. ${ }^{14}$ More generally, linkage can translate into a loss of sovereignty and thus reduced autonomy for the linking jurisdictions. A broader concern is that, from a game-theoretic perspective, the possibility of linkage can induce parties to put in place less ambitious national targets so as to create cheap surplus units that their firms could sell into the linked market. ${ }^{15}$

The economic argument for linkage suggests that we would expect to observe linkages between political jurisdictions with widely divergent marginal costs of abatement (or, equivalently, shadow prices of carbon ${ }^{16}$ ). To date, linkage agreements, whether enacted or under discussion, have been between jurisdictions with relatively similar carbon prices (for example, California, Québec, and Ontario) undercutting the major economic argument for linkage. These linkages may be driven by political and administrative benefits more than economic benefits. The political benefits from linking policies may stem from such linkage providing a sense of momentum to which political supporters of climate policy can point and so build support. ${ }^{17}$ And once a link has

10 World BAnK, Ecofys \& Vivid ECONOMics, State AND TrEnds of CARbon Pricing 2016 (2016), https://perma.cc/NVZ9-Q6GX.

11 Christian Flachsland, Robert Marschinski, \& Ottmar Edenhofer, To Link or Not to Link: Benefits and Disadvantages of Linking Cap-and-Trade Systems, 9 CLIMATE POL'Y 358 (2009); Matthew Ranson \& Robert N. Stavins, Post-Durban Climate Policy Architecture Based on Linkage of Cap-and-Trade Systems, 13 CHI. J. INT'L L. 403 (2013)

12 Bodansky et al., supra note 5.

13 Judson Jaffe, Matthew Ranson, \& Robert Stavins, Linking Tradable Permit Systems: A Key Element of Emerging International Climate Policy Architecture, 36 ECOLOGY L.Q. 789 (2009).

14 Matthew Ranson \& Robert N. Stavins, Linkage of Greenhouse Gas Emissions Trading Systems: Learning from Experience 1-36 (Harvard Project on Climate Agreements, Discussion Paper ES 2013-2, 2013), https://perma.cc/L3UX-CWKJ.

15 Carsten Helm, International Emissions Trading with Endogenous Allowance Choices, 87 J. PUB. ECON. 2737 (2003). See also the broad critique of linking in Jessica F. Green, Don't Link Carbon Markets, 543 NATURE 484 (2017).

16 "Shadow price" refers to the cost to an economy of reducing emissions by one ton through regulation. Regulatory actions to reduce emissions (for example, fuel economy or carbon intensity standards) impose a cost per ton of emissions reductions. Because this cost is not explicitly observed (as a tax rate or allowance price), it is referred to as a shadow price.

17 See Bodansky et al., supra note 12. 
been established, it may create path dependency that favors continued climate action, given barriers to termination of a link. ${ }^{18}$ Since greenhouse gas emissions are a global pollutant, no politician wants to appear to be acting unilaterally to control emissions. Linking with other jurisdictions is a tangible signal of a multilateral approach to the climate problem.

There are also administrative economies of scale through linkage. Jurisdictions can share best practices in designing and operating emission control policies and so learn from each other. They can also share administrative and oversight costs and so avoid costly duplication of control efforts. This can be especially important for smaller jurisdictions which can piggy-back on the existing administrative structure of programs in larger jurisdictions with which they link.

Since the primary economic argument for linkage is equalization of carbon prices across political jurisdictions, it is worth noting that agreements could also be made to harmonize carbon prices. We distinguish between hard linkage, defined above as a formal recognition by a GHG mitigation program in one jurisdiction (a regional, national, or sub-national government) of emission reductions undertaken in another jurisdiction for purposes of complying with the first jurisdiction's mitigation program, and soft linkage. Soft linkage is an agreement (explicit or implicit) to harmonize carbon prices either at a given price or within some band. ${ }^{19}$

Soft linkage could be accomplished in a number of ways, including a carbon $\mathrm{club}^{20}$ or an agreement among countries to set a common price band for unlinked cap and trade programs. A price band is achieved by setting a price collar, or a combination of a price ceiling, typically implemented through a safety valve price at which the government agrees to sell allowances to all comers, and a price floor, which can be established through a reserve price on the auctioning of new allowances. Countries might also agree on overlapping price bands where certain sets of countries are allowed a lower price band than others.

Such soft linkage can preserve the economic benefits of price harmonization while not requiring the formal administrative structure nor oversight of trading to avoid double-counting of emission reductions for reporting of Internationally Transferred Mitigation Outcomes (ITMOs). It can also provide the political benefits of co-ordination and momentum building across political jurisdictions that may be important as the Paris Agreement is initially implemented and efforts to raise ambition proceed.

That said, our major focus in this paper is on ways in which linkage design involving crossborder transfers can be used to help countries implement and achieve their NDCs under the Paris Agreement. Therefore, we focus - for the most part - on hard linkage systems, with just one of the five cases we later explore being an example of soft linkage.

\section{Forms of Heterogeneity that CAN AfFeCt Linkage of Climate Policies}

Policies have many attributes in their design, but for purposes of our analysis, it is helpful initially to separate these attributes into three categories: policy instrument; political jurisdiction; and target. We further divide our consideration of political jurisdiction into two types of heterogeneity - level of government engaged in the policy and prospective linkage (regional, national, or sub-

18 William Pizer \& Andrew Yates, Terminating Links between Emission Trading Programs, 71 J. ENV. ECON. \& MGMT. 142 (2015).

19 On the rationale for such a price band, see CARBon Disclosure ProjeCt North AMERICA, CARBon PRICING CORRIDORS: THE MARKET VIEW (2017), https://perma.cc/GF5R-FV7L.

20 William D. Nordhaus, Climate Clubs: Overcoming Free-riding in International Climate Policy, 105 AMER. ECON. REV. 1339 (2015). 
national), and status under the Paris Agreement (Party or non-Party). Also, our consideration of the type of target is divided into two distinct issues - the type of policy-instrument target, and the type of NDC target. We examine options within each of these five categories in turn.

\section{A. Heterogeneity of Policy Instruments}

Four major types of policy instruments have been implemented, planned, or at least proposed to reduce GHG emissions: trading systems (cap-and-trade systems, as well as emission-reductioncredit systems); taxes; performance standards; and technology standards. Of the major types of policy instruments, all but technology standards may be linked, essentially through mutual recognition and crediting for compliance. Linkage can occur between cap-and-trade and tax systems, between either of those systems and non-market regulatory (performance-standard) systems, or among non-market regulatory systems. ${ }^{21}$

As of 2018, around $15 \%$ of global GHG emissions were covered by carbon-pricing regimes - emissions trading and carbon taxes - with the number of implemented systems having increased from two in 1990 to about 45 in $2017 .{ }^{22}$ Actual carbon prices are - for the most part - higher in tax systems than in trading systems, but the emissions coverage of trading systems is much greater. ${ }^{23}$ These implemented and planned systems are largely found in the member countries of the Organisation for Economic Co-operation and Development ("OECD") plus a few others. When China's national $\mathrm{CO}_{2}$ emissions trading system, which is being phased in by 2020 , reaches its full scale covering half of the country's emissions, the share of global emissions subject to carbon pricing will increase from $15 \%$ to between 20 and $25 \%$.

In the context of the Paris Agreement, some two-thirds of Parties, accounting for $58 \%$ of global GHG emissions, stated in their initial NDCs under the Agreement that they are considering the use of carbon pricing to achieve their NDC targets. ${ }^{24}$ In this case, the geographic distribution is much broader than for implemented or even planned carbon-pricing systems, and includes many developing countries.

\section{Links between Cap-and-Trade Systems}

Cap-and-trade programs provide the most straightforward opportunity for linkage, by allowing firms (emission sources) in one jurisdiction to comply either with local allowances or equivalent

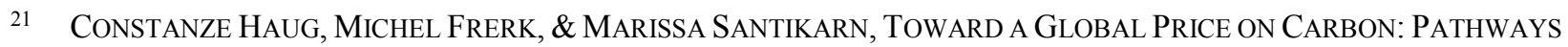
FOR LINKING CARBON PRICING INSTRUMENTS (2015), https://perma.cc/6YS9-BDJ5; Gilbert E. Metcalf \& David Weisbach, Linking Policies When Tastes Differ: Global Climate Policy in a Heterogeneous World, 6 REV. ENV. ECON. \& Pol'y 110 (2012); Robert W. HAHn \& Robert N. Stavins, What Has the Kyoto Protocol Wrought? THE REAL ARCHITECTURE OF InTERNATIONAL TRADEABLE PERMit MARKETS (1999).

22 World Bank, Ecofys \& Vivid Economics, State AND Trends of CARbon Pricing 2017, 13 (2017), https://perma.cc/GQ4Y-W433.

23 In implemented carbon-pricing systems, carbon prices (either market-determined allowance prices in cap-andtrade systems or tax rates in carbon tax systems) vary greatly - from less than $\$ 1$ to more than $\$ 140$ per ton of $\mathrm{CO}_{2}$ equivalent, see WORLD BANK et al., supra note 22, at 14; for a discussion of the role of market mechanisms under the Paris Agreement, see HANNA WANG-HELMREICH et al., POTENTIALS AND LiMITATIONS OF DIFFERENT Requirements (OFfSetting) IN Bilateral AND Global CARbon Pricing Systems (2017), https://perma.cc/Y3YD-E3BA.

24 WORLD BANK et al., supra note 22. 
allowances from another, linked system. These and other linkages involving transfers across jurisdictions (hard linking, as defined above) can be direct or indirect. In the case of cap-and-trade systems, direct linkage occurs between two systems when one participating jurisdiction agrees to accept allowances from the other jurisdiction for purposes of compliance with the local cap. Indirect linkage occurs when two systems do not accept allowances from each other, but both accept allowances from a common third party. ${ }^{25}$ Direct linkage can occur on a one-for-one basis, where an allowance from one jurisdiction is accepted in place of an allowance for the same amount of emissions in another jurisdiction, ${ }^{26}$ or a trading ratio (exchange rate) can apply to allowance transfers between the two systems. ${ }^{27}$

The political challenges of implementing a set of exchange rates could be considerable, in part because such exchange rates might be seen as representing a value judgment regarding the environmental integrity of emissions reductions claimed by a Party's domestic policy instrument. Furthermore, while exchange rates can facilitate linking programs with different levels of ambition (and carbon prices), they blunt, if not eliminate, the economic benefits of linkage by preventing the equalization of carbon prices across jurisdictions. ${ }^{28}$ The political and administrative benefits remain, however, and the use of exchange rates could be designed with a phase-out so that allowances trade at parity after some designated period of time.

Direct linkage can be bilateral (two-way), where both systems accept allowances or credits from the other system for compliance, or unilateral (one-way), where only one of two systems allows credits from the other for compliance. ${ }^{29}$ Even with the straightforward case of a linkage between two cap-and-trade systems, a number of issues can arise. ${ }^{30} \mathrm{We}$ discuss these issues later in our analysis of key cases of potential climate policy linkages.

\section{Links between Heterogeneous Policy Instruments}

By the time the Paris Agreement was adopted in December, 2015, 20 regional, national, or subnational $\mathrm{CO}_{2}$ cap-and-trade systems were either operating or scheduled to launch in 40 countries. These include the European Union Emissions Trading System ("EU ETS"), the Regional Greenhouse Gas Initiative ("RGGI") in the northeast United States, seven regional pilots in

25 Ranson et al., supra note 11.

26 Ranson et al., supra note 11; Ranson et al., supra note 14.

27 If systems wish to preserve different levels of ambition, they can put in place a number of mechanisms to do so. First, they can recognize allowances from the other jurisdiction with an exchange rate. For example, a country with a more aggressive cap might agree to accept allowances from a country with a less aggressive cap but apply an exchange rate so that, for example, three tons of emission allowances from the other country would be required for one ton of compliance domestically, see Dallas Burtraw, Karen L. Palmer, Clayton Munnings, Paige Weber \& Matthew Woerman, Linking by Degrees: Incremental Alignment of Cap-and-Trade Markets (Resources for the Future Working Paper RFF DP 13-04, April 2013), https://perma.cc/6MY2-PB3V. Second, a country can place a limit on the use of allowances from other systems. Third, a country could require a payment to "top up" each foreign allowance approved for compliance purposes. For example, if an allowance from a system with a less ambitious cap (and an allowance price of $\$ 10$ ) were used for compliance in a system with a more ambitious cap (and an allowance price of \$25), the complying entity in the second system could be required to surrender the foreign allowance together with a payment of $\$ 15$ to account for the difference. Note that the fee in this type of top-up approach could be set below the difference in allowance value (i.e., at less than $\$ 15$ in the example given) to preserve some positive incentive for trading, see Bodansky et al., supra note 5.

28 Lambert Schneider, Michael Lazarus, Carrie Lee \& Harro van Asselt, Restricted Linking of Emissions Trading Systems: Options, Benefits, and Challenges, 17 InT’L EnVTL. Agr.: Pol., L. \& Econ. 1 (2017).

29 Ranson et al., supra note 11.

$30 \quad$ Jaffe et al., supra note 13; Ranson et al., supra note 11; Burtraw et al., supra note 27. 
China, ${ }^{31}$ and emissions trading systems in California, Kazakhstan, New Zealand, Québec, Switzerland, and Tokyo. ${ }^{32}$ Of these, most had established or proposed at least one international linkage with another cap-and-trade or credit system.

Not all countries will employ cap-and-trade instruments as their means of reducing GHG emissions under the Paris Agreement, however. Other instruments include carbon taxes or fees, emission reduction credit ("ERC") or offset systems, such as the Kyoto Protocol's Clean Development Mechanism ("CDM"), and traditional regulatory approaches, including performance standards and technology standards. In this context, we think of linkage as a means of narrowing or eliminating differences in the actual or shadow price of carbon (the marginal cost of abatement) through policies that allow carbon regimes in different political jurisdictions to interact in various ways.

Consider linkage between a cap-and-trade system and a carbon tax system. Firms under a cap-and-trade program could sell allowances to firms required to pay the carbon tax, allowing the purchasing firm to lower its tax obligation by the amount of allowances it submits for retirement. Operationally, firms could be allowed to exempt from their carbon tax base any emissions for which they have allowances that they surrender in the taxing jurisdiction. The national accounting for UNFCCC reporting purposes need be no different than the accounting for allowance transfers between two linked cap-and-trade programs. There would be an appropriate adjustment in the two Parties' national inventories for the aggregate amount of allowances used in the tax system.

For two-way linked systems, firms might be allowed to pay taxes at a higher level than they owe based on their emissions and in return receive certified Emission Tax Payment Credits ("ETPCs") from their government that they could sell to firms that are operating under a cap-andtrade program. Within the cap-and-trade program, firms could use ETPCs just as they would the equivalent quantity of allowances for purposes of compliance. Since the use of ETPCs relaxes the cap in the cap-and-trade system in return for a payment to the other system, symmetry with the treatment of allowance trading (or allowance use in a linked cap-and-trade with tax system) would suggest that national inventories would be adjusted such that the mitigation obligation in the capand-trade system is relaxed by the amount of ETPCs used while the mitigation obligation in the carbon tax system is tightened similarly. The two systems might agree, however, to a different arrangement. They might agree not to adjust their national inventories at all or make a partial adjustment conditional on the sum of the inventories remaining unchanged. Whatever arrangement is agreed upon would be communicated to the appropriate UNFCCC body as part of national reporting by each party.

Likewise, either a carbon tax or a cap-and-trade system could be linked with policies that provide subsidies for emissions reductions, which could be traded like ERCs to be used in place of allowances to comply with a cap-and-trade program, or as ETPCs for compliance with a carbon $\operatorname{tax}^{33}$

31 An eighth pilot system was launched in 2016 by the government of Fujian Province (but not mandated by China's National Development and Reform Commission).

32 International CARbon ACtion PARTNERship (ICAP), EMissions TRADING WorldWide: Status Report 2018 (2018), https://perma.cc/T4U9-ASMR; WORLD BANK \& ECOFYS, STATE AND TRENDS OF CARBON PRICING 2014 (2014), https://perma.cc/RPA3-CJLN.

33 See Metcalf et al., supra note 21; for example, Mexico's carbon tax in principle allows the use of offset credits from projects under the Kyoto Protocol's Clean Development Mechanism ("CDM") in lieu of tax payments, although the rules to render this link operational have yet to be elaborated, see International Carbon Action Partnership, Mexico Announces ETS Plans and Introduces a Carbon Tax, ICAP NEWSLETTER (Issue 2, June 12, 2014), https://perma.cc/VNX8-C592; WANG-HELMREICH et al., supra note 23. 
In principle, market-based mechanisms ${ }^{34}$ (mainly taxes and cap and trade) could be linked with a performance-based regulatory system. If the regulation is in the form of a quantity standard (for example, tons of carbon-dioxide-equivalent reduction), firms could buy allowances or ETPCs from another market to meet the required quantity of reduction, or achieve reductions in excess of the regulatory minimum and then sell additional reductions as ERCs. As we discuss later in our examination of heterogeneity in types of NDC targets, intensity standards may be translated into quantity standards at the source or firm level (per total output, total sales, or whatever denominator the regulation prescribes), thus allowing for linkage. ${ }^{35}$

Technology standards present a considerably greater challenge, because it is difficult to verify the additionality of emissions reductions from meeting or exceeding a technology standard. Even a one-way link, which might allow firms facing the technology mandate to purchase offsets or allowances from another system, would be challenging to implement. In principle, credits could be used to attribute reductions to companies that outperform expected emissions reductions from a technology standard; these credits could then be sold to foreign markets. ${ }^{36}$ However, the degree of uncertainty of emissions impacts of technology standards argues against linking such systems.

In addition to heterogeneity regarding the type of instrument, climate policies can also differ in terms of the legal nature of instruments. Differences can be with regard to the degree of formality of instruments and the position of implementing rules in the hierarchy of norms, as well as in the degree of normativity, that is, whether an instrument is legally binding or not.

Regarding the degree of formality, differences can relate to whether a climate policy instrument has been adopted at a relatively higher level in the normative hierarchy, such as a formal statute adopted by a national legislature, or at a lower level, such as an executive order or administrative decree. A higher degree of formality will typically mean that the instrument is more resilient to political and judicial challenge, and that it takes precedence over lower level rules in the event of conflict. ${ }^{37}$ This tends to afford the policy greater certainty and predictability, which may influence a linking partner when deciding whether or not to link.

As for the degree of normativity, legally binding force means that adherence is not optional as a matter of law, with violations carrying the threat of punitive sanctions enforced by public authorities. ${ }^{38}$ While most climate policy instruments are mandatory, several countries (for example, South Korea, Switzerland and the United Kingdom) have relied on voluntary instruments before transitioning to mandatory policies.

Generally speaking, differences in the degree of formality and normativity need not be obstacles to linking, although informal or voluntary instruments will tend to offer a lower assurance of compliance and reduced accountability of participating entities. Taken together, these

34 We define market-based mechanisms as policy instruments that alter the price of emitting activities relative to non-emitting activities. Examples include taxes and cap-and-trade systems that explicitly price emissions, as well as subsidies for clean technologies (feed-in tariffs and renewable portfolio standards) that alter the price of nonemitting energy sources relative to emitting sources. Market-based approaches do not prohibit emissions by individual firms; rather they put a common price on emissions at the margin. The result - in a well-designed system - can be cost-effective (cost-minimizing) achievement of the environmental target.

35 Metcalf et al., supra note 21.

36 Metcalf et al., supra note 21.

37 While specific circumstances will differ from jurisdiction to jurisdiction, a higher degree of formality also tends to entail a more onerous adoption procedure, such as passage by various committees and approval by one or more legislative chambers with a specified majority vote.

38 Because of these potential consequences, the heightened normativity of legally binding rules is typically premised on observance of strict, formal requirements, such as a suitable legal basis and specific adoption procedures, with mandatory content worded in clear and determinate language. 
uncertainties diminish the predictability of policy outcomes, and can affect the confidence and trust instilled in potential linking partners.

\section{Experience with Linkage of Climate Policy Instruments}

As of now, climate policy linkages have largely - but not exclusively - been between trading systems (Table 1). The first panel in the table lists former, existing, and planned direct linkages between mandatory cap-and-trade systems. ${ }^{39}$ There have been two cases of planned one-way linkages, both now abandoned. One was Australia's plan to accept EU ETS allowances beginning in July, 2015. Due to political changes in the country, however, Australia rescinded its existing carbon tax and planned cap-and-trade system in July, 2014, which terminated the announced linkage. The other example of one-way linkage was the language in RGGI's 2006 amendment to its Memorandum of Understanding that made it possible, subject to further approval, for participants to use allowances from foreign cap-and-trade systems when and if RGGI allowance prices exceeded a specified trigger price (the trigger price started at $\$ 10$ per ton of $\mathrm{CO}_{2}$ in 2005 , and increased by roughly 2 percent each year). Because RGGI prices remained well below the trigger price, this one-way linkage option was never exercised. The 2013 updates to the RGGI Model Rule ended this conditional linkage. ${ }^{40}$

Importantly, Table 1 includes the prominent 2014 linkage between California's, Ontario's, and Québec's cap-and-trade systems, under which their respective systems are not only linked, but also tightly harmonized, and hold joint allowance auctions. ${ }^{41}$ Although Australia formerly had plans for a two-way linkage with the EU ETS beginning in 2018, the repeal of Australia's capand-trade system ended this link as well. ${ }^{42}$ While these are not always characterized as linkages, we include in Table 1 what we consider two examples of multilateral linkage: among the EU ETS nations and among the RGGI states. While these are not technically linkages between independent cap-and-trade systems, they involve national or sub-national jurisdictions participating in an integrated, cross-border carbon market. Because of the similarities to linkage, it can be useful to think of such systems as sets of linked cap-and-trade programs (Ellerman and Buchner 2007).

The second panel in Table 1 lists (one-way) linkages in which cap-and-trade systems accept offsets from ERC systems. By far the most important credit system, in terms of the volume of credits created, is the Kyoto Protocol's CDM. Several cap-and-trade systems, including those of the EU, Switzerland, and New Zealand, have established such one-way linkages. Of these, the EU

39 The two-way linkages described in Table 1 can be bilateral or multilateral. We distinguish them in the table by denoting the former as "Two-way" and the latter as "Multilateral." The multilateral linkages are all two-way.

40 Regional Greenhouse Gas Initiative, Summary of RGGI Model Rule Changes (Feb. 2013), https://perma.cc/3S2VEFUT.

41 See Agreement on the Harmonization and Integration of Cap-and-Trade Programs for Reducing Greenhouse Gas Emissions, Calif., Ont. and Québ., adopted Sept. 22, 2017, https://perma.cc/PF7P-ZCVN. Linkage between these jurisdictions occured under the auspices of the Western Climate Initiative ("WCI").

42 See, New Australian Government Dismantling Climate Policies, ClimATEWIRE (Sept. 12, 2013), https://perma.cc/2H8Q-UUNJ. Less defined, but a potential precursor of a bilateral linkage, is a Memorandum of Understanding (MOU) signed in 2014 by the Governor of California and the government of Mexico to coordinate climate policy efforts, including the possible development and implementation of "carbon pricing systems and other market-based instruments", Debra Kahn, Gov. Brown Signs Pact to Work with Mexico on Carbon Pricing and other Climate, Environmental Programs, CLIMATEWIRE (July 29, 2014), https://perma.cc/EUS9-CKMF. Also, in 2013, California, Oregon, Washington, and British Columbia established the Pacific Coast Collaborative to coordinate climate policies. In addition, a relevant MOU exists between the governments of Québec and Mexico. 
has been the dominant purchaser of CDM credits: as of 2011, over 80 percent of issued CDM Certified Emissions Reductions (CERs) were used by EU ETS compliance entities or were being held in EU carbon registry accounts. ${ }^{43}$

The third panel in Table 1 lists examples of a link between heterogeneous policy instruments, namely a carbon tax that allows the use of offsets generated within the same or a different jurisdiction. Under Mexico's carbon tax on fossil fuels, ${ }^{44}$ firms will be able to use offset credits from domestic CDM projects developed in Mexico to meet all or part of their tax liability. ${ }^{45}$ South Africa has planned to allow offsets to be used in lieu of tax payments when its carbon tax goes into effect, ${ }^{46}$ and Chile is considering a similar option for its carbon tax. ${ }^{47}$

In addition to the system-level linkages shown in Table 1, some nations have participated in a different form of cross-border transfers via the trading of Assigned Amount Units (AAUs) under the Kyoto Protocol's Article 17. The Protocol assigns each Annex I Party a quantity of AAUs equal to its GHG emissions target for a given commitment period, measured in metric tons of $\mathrm{CO}_{2}$-equivalent. The Protocol then requires each Annex I Party, at the end of a commitment period, to surrender enough AAUs to cover its actual emissions over the period. If a country's emissions exceed its AAUs, it is allowed to make up the difference by purchasing AAUs from another country under Article 17 of the Kyoto Protocol or by obtaining emissions credits under one of the Protocol's project-based mechanisms - Joint Implementation and the CDM. ${ }^{48}$ While both AAU trading and linkage involve cross-border transfers, the former occurs within a single governance framework created by the Kyoto Protocol, with countries as market participants, while the latter occurs between different national or subnational policies, and can involve a variety of actors as market participants.

In principle, AAU trading between nations creates implicit linkages between their domestic carbon abatement policies. In practice, however, the market for AAUs has involved a very limited number of participants. This should not be surprising, given that governments are not simple costminimizing entities and lack necessary information about abatement costs. ${ }^{49}$ There have also been a few instances of partial and unconventional linkage, including some cases of what Burtraw et al. refer to as "linking by degrees." ${ }^{50}$ Such linkages have occurred when jurisdictions have taken

43 Igor Shishlov and Valentin Bellassen, 10 Lessons from 10 Years of the CDM (CDC Climate Climate Report 37, 2012), https://perma.cc/D7RR-T4XZ. Other proposals for offset programs exist. California has negotiated a Memoranda of Understanding with the provinces of Acre, in Brazil, and Chiapas, in Mexico, to work together to develop a framework to allow the use of offsets from those states in California's cap-and-trade system under AB 32.

44 The tax was initially set at $\$ 3.50$ per ton of carbon dioxide equivalent $\left(\mathrm{tCO}_{2} \mathrm{e}\right)$.

45 WORLD BANK et al., supra note 32.

46 Brendon Bosworth, Offsets to Cushion South African Carbon Tax, InTER Press SERVICE News Agency (May 2014), https://perma.cc/YTZ9-GFKJ.

47 WANG-HELMREICH et al., supra note 23.

48 Kyoto Protocol to the United Nations Framework Convention on Climate Change, Dec. 10, 1997, U.N. Doc FCCC/CP/1997/7/Add.1, 37 I.L.M. 22 (1998) [hereinafter Kyoto Protocol].

49 HAHN ET AL., supra note 21; most AAUs have been purchased by Japanese firms, the government of Spain, or the World Bank. Other buyers have included Austria, Belgium, Ireland, Japan, Luxembourg, the Netherlands, Portugal, and one U.S. firm. Virtually all transactions occurred between 2008 and 2012, and involved sales by economies in transition -specifically, central and eastern European countries. The sole exception was a very small sale of AAUs by New Zealand in 2010, see Ranson et al., supra note 14.

50 Burtraw et al., supra note 27. 
actions that fell short of establishing a formal link but nonetheless brought their systems into closer alignment. $^{51}$

As noted above, linkages among carbon tax systems can be direct or indirect. Carbon taxes are currently in place or planned in British Columbia, Chile, Denmark, Finland, France, Iceland, Ireland, Japan, Mexico, Norway, South Africa, Spain, Sweden, Switzerland, and the United Kingdom. Some of these taxes have been expressly introduced with the intention of complementing the carbon price established by a cap-and-trade system by, for example, extending a carbon price to sectors not covered by an existing cap-and-trade system.

\section{Lessons Learned from Experience with Linkage of Climate Policy Instruments}

Experience to date with explicit and implicit linkages of carbon policies across jurisdictions yields some potentially useful lessons. ${ }^{52}$ First, a number of regions, nations, and sub-national jurisdictions have demonstrated their preference for linkage, despite the challenges. Second, linking carbon markets has proved, in the words of a World Bank report, "powerful and effective," although the risks of linking include that problems in one market can be transferred via linkage to other systems. ${ }^{53}$ Specifically, the World Bank report cites the link between the New Zealand cap and trade system and the CDM market as critical for keeping costs in the New Zealand system down. Similarly, the report notes that CER prices were "heavily dependent" on the EU ETS price, and this helped to get the CDM market up and running. Third, although there was value to firms in Annex I countries (with emissions reduction commitments) under the Kyoto Protocol from their use of CDM offsets for purposes of cost mitigation, a functioning international market for such offsets does not appear likely to continue, particularly given restrictions on the use of such offsets in the EU ETS. ${ }^{54}$ Fourth, the International Transaction Log, part of the Kyoto Protocol process, played a valuable role by tracking traded units and preventing double counting. ${ }^{55}$

Fifth, linkages are not permanent, as both the linkages themselves and the policies to be linked can be vulnerable to national or sub-national political swings (as occurred in Australia and

51 Examples include Australia and California signing a memorandum of understanding in 2013 on sharing information and experience with cap-and-trade systems and with linkage. Similarly, California and RGGI have engaged in information sharing and have adapted some design elements from each other (Burtraw et al., supra note 27), while the state of Washington and the United Kingdom have engaged in a partnership to collaborate on carbon-market design, as well as other issues, see State of Washington and United Kingdom Department of Energy and Climate Change, Report on the Collaboration between Washington State and the UK Government on Climate Change (July 14, 2014), https://perma.cc/9G4X-9DNJ. Other examples include bilateral arrangements between the EU and China, the European Bank for Reconstruction and Development (EBRD) and Kazakhstan, Germany and Mexico, and many others which have provided capacity building, analytical and technical support, and financial assistance to accelerate the deployment of carbon trading policies in emerging and transition economies, see Katja Biedenkopf, Patrick Müller, Peter Slominski \& Jørgen Wettestad, A Global Turn to Greenhouse Gas Emissions Trading? Experiments, Actors, and Diffusion, 17 GloBAL ENVTL. POL. 1 (2017).

52 Andreas Tuerk, Michael Mehling, Christian Flaschland \& Wolfgang Sterk, Linking Carbon Markets: Concepts, Case Studies, and Pathways, 9 CLIMATE POL'Y 341 (2009); Ranson et al., supra note 14; Richard Newell, William Pizer \& Daniel Raimi, Carbon Markets 15 Years after Kyoto: Lessons Learned, New Challenges, 27 J. ECON. PERSPECTIVES 123 (2013); Bodansky, supra note 5.

53 WORLD BANK et al., supra note 32.

54 European Commission, Proposal for a Decision of the European Parliament and of the Council Concerning the Establishment and Operation of a Market Stability Reserve for the Union Greenhouse Gas Emission Trading Scheme and Amending Directive 2008/87/EC, COM(2014) 20 final (Jan. 22, 2014), https://perma.cc/D7JZ-ZJDP.

55 Andrei Marcu, The Role of Market Mechanisms in a Post-2020 Climate Change Agreement (Centre for European Policy Studies Special Report 87, May 2014), https://perma.cc/Z3R8-BRXR. 
the United States). This causes uncertainty for regulated firms. ${ }^{56}$ Sixth and finally, the benefits and attraction of linkage are likely to evolve over time. In the short run, the benefits may be more political and administrative than economic ${ }^{57}$ Perfect price (or shadow price) convergence is unlikely in the short run under many linkages, given restrictions on the magnitude of allowance flows observed in most linkage schemes (Table 1). In the long run, however, as markets mature and countries adopt more ambitious mitigation targets, it may be reasonable to expect some loosening of constraints on linkage flows, contributing to enhanced price harmonization and greater cost-effectiveness of carbon policy. ${ }^{58}$

\section{B. Heterogeneity of Jurisdictions}

Two types of jurisdictional heterogeneity are relevant for international linkage in the context of the Paris Agreement - level of government jurisdiction, and status of that jurisdiction as a Party (or located geographically within a Party in the case of sub-national jurisdictions) or non-Party of the Paris Agreement.

\section{Level of Jurisdiction}

It is broadly recognized that the fact that GHGs mix in the atmosphere renders climate change a global commons problem. This, in turn, suggests that: global cooperation will be necessary to address the problem successfully; and the highest levels of effective governance need to be engaged in executing effective policies. On this basis, the countries of the world are the appropriate actors for engaging in such cooperation. International relations are primarily conducted between countries, and they can work through international arrangements such as the UNFCCC and the Paris Agreement, and through regional economic integration organizations such as the European Union, to address climate change. For international climate policy linkage, relevant levels of jurisdictions therefore include - at a minimum - countries and regional organizations (the EU).

In addition, a number of sub-national jurisdictions - in particular, state and provincial governments - have put in place, are planning, or are contemplating the launch of meaningful climate change policies, including cap-and-trade systems, carbon taxes, and various kinds of conventional standards. In some cases, these may function as substitutes for or supplements to national policies (for example, in the United States); and in other cases, these sub-national policies will function as part of integrated national systems (as in Canada). Furthermore, in some countries, including Japan and the United States, cities may come to play significant policy roles. Hence, a

56 Ranson et al., supra note 14; Pizer et al., supra note 18.

57 Burtraw et al., supra note 27.

58 We conjecture that linkage may lead indirectly to price harmonization. Here is an example for two countries with cap-and-trade systems. Country A has a cap-and-trade system in place with a current allowance price in the $\$ 15$ per ton range. Now assume country B decides to set up a cap-and-trade system and, for political and administrative reasons, decides it would like to link to country A's system. Country B might decide, as part of it design process, to set a cap so that its expected allowance price is close to that of country A. In effect, country A serves as a carbon-pricing leader and country B follows that lead as it negotiates a linked system. Once the countries link their systems, it may appear that there was no economic benefit from linking, given their similar carbon prices. But if our conjecture is correct, then linkage opportunities in such situations do in fact provide economic as well as political and administrative benefits. The alignment of prices occurred in this instance through program design rather than through trading in sufficiently deep markets. Whether or not this conjecture is empirically valid is left as a future research topic. 
third important jurisdictional level for potential linkage - in addition to the international and regional - is the sub-national. This could, under the right conditions, become a particularly important level for future linkage in light of the U.S. administration's announcement that it will withdraw from the Paris Agreement. ${ }^{59}$

It is demonstrably true that effective sub-national climate policy linkages are feasible in the physical and economic senses, as such linkages have existed and operated for some time, both within a single country in the case of the RGGI states, ${ }^{60}$ and internationally in the case of California and Quebec (Table 1). Taking the California-Quebec link as an example, if there were no international climate agreement in force, then the only major issue would be whether doublecounting is avoided both at the sub-national and the national level, as each jurisdiction quantifies its emissions inventory and accounts for progress towards mitigation goals. At the sub-national level, the California-Quebec link ensures proper accounting through close coordination of the systems (Görlach et al. 2015).

An international climate agreement is very much in place, however, and this gives rise to important questions of international law. Because sub-national entities are not currently allowed to join the UNFCCC and the Paris Agreement as formal Parties, ${ }^{61}$ their emissions have to be accounted for and reported at the national level. Ensuring consistency between the sub-national and national level is therefore up to the country of which the sub-national entity forms part. To the extent that Parties to the Agreement seek to use ITMOs, including any ITMOs transferred between their sub-national jurisdictions, towards their NDCs, such accounting would need to be consistent with the Agreement, including any guidance on accounting adopted by the Parties.

Additionally, Article 6.3 of the Agreement states that use of ITMOs towards NDC achievement shall be "authorized by participating Parties." While this does not, for instance, preclude trading across the link between California and Quebec, it does require both Canada and the U.S. - as the participating Parties - to authorize the use of transferred allowances toward national NDC achievement. If the U.S. withdraws from the Paris Agreement, as it has announced, Canada may be precluded from counting Californian allowances when it measures progress towards its NDC goals (for further discussion, see below, Section II.B.2).

Also, legal and procedural constraints imposed by national law can limit the types of arrangements available to sub-national jurisdictions when these establish a link. The U.S. Constitution, for example, expressly reserves the ability to adopt binding international treaties to the Federal Government, ${ }^{62}$ which means that the arrangement California entered with Ontario and Quebec in 2017, despite being designated an "agreement", lacks the binding legal force of an

59 Michael D. Shear, Trump Abandoning Global Climate Accord, N.Y. TIMES (June 1, 2017), A1.

60 Richard L. Schmalensee \& Robert N. Stavins, Lessons Learned from Three Decades of Experience with Cap and Trade, 11 REV. ENVTL. ECON. \& POL'Y 59 (2017).

61 Sovereign countries and certain international organizations (such as the EU) have traditionally been the main subjects of international law, see ANTHONY AUST, MODERN TREATY LAW AND PRACTICE 55 ( $3^{\mathrm{d}}$ ed. 2014), although there are examples of treaties with and between sub-national jurisdictions, see Duncan B. Hollis, Why State Consent Still Matters: Non-State Actors, Treaties, and the Changing Sources of International Law, 23 BERKELEY J. INT'L L. 137, 146 (2005).

62 Under U.S. CONST. art. II, § 2, cl. 2, only the President "shall have Power, by and with the advice and consent of the Senate, to make treaties, provided two-thirds of the Senators present concur". In art. I, § 10, the Constitution goes on to expressly prohibit any state from entering into a "treaty, alliance, or confederation" or from entering "without the Consent of Congress ... into any Agreement or Compact ... with a foreign Power." For further discussion and secondary sources, see Michael A. Mehling, Linking of Emission Trading Schemes, in LEGAL Aspects of CARbon Trading: Kyoto, Copenhagen, AND Beyond 108 (David Freestone \& Charlotte Streck eds., 2009). 
international treaty. While the agreement has been implemented in each jurisdiction through subnational rules and its provisions therefore have acquired legal force, California, Ontario and Quebec retain the right to unilaterally amend their laws and regulations, including termination of the link. ${ }^{63}$ A binding international treaty, by contrast, could only be amended or terminated subject to the conditions set out in the treaty itself, and would offer additional recourse to each Party in the event of a breach of obligations.

In addition, national law can impose substantive restrictions on linkages at the sub-national level. To draw again on the U.S. for an example, scholarly debate has discussed whether U.S. federal law limits the ability of states to introduce and link sub-national climate policies through the dormant Commerce Clause, a provision in the Constitution which prevents states from interfering with interstate commerce. ${ }^{64}$

\section{Status under the Paris Agreement}

Two considerations arise for potential international linkages with regard to the status of the affected jurisdictions under the Paris Agreement. First, there is the question of whether a specific regional economic integration organization (such as the European Union) or country is a Party to the Agreement. This question is of interest primarily because of the U.S. administration's announcement that it will withdraw from the Paris Agreement. ${ }^{65}$

Second, as described above, sub-national jurisdictions may play important climate policy roles in the future. Given the broad membership of the Paris Agreement, such sub-national jurisdictions will more often than not be located within a Party to the Agreement, as is currently the case with Canadian provinces. If Canada wants to use any ITMOs transferred at the subnational level (for example, through climate policy links between Canadian provinces and a foreign jurisdiction) towards achievement of its NDC, the required authorization and accounting will have to occur at the national level (see Section II.B.1). But in some cases, one or both of the sub-national jurisdictions might be located within a non-Party to the Agreement, as would be the case for California if the United States withdraws from the Agreement.

As already discussed in Section II.B.1, whether and how non-Parties (or sub-national jurisdictions located within non-Parties) can participate in ITMO transfers under Article 6 of the Agreement is still subject to debate. While the wording of Article 6.3 clearly states that only the use of ITMOs to achieve NDCs requires authorization by participating Parties - suggesting, $e$

63 Both parties acknowledge this in the preamble when they state that "the present Agreement does not, will not and cannot be interpreted to restrict, limit or otherwise prevail over relevant national obligations of each Party, if applicable, and each Party's sovereign right and authority to adopt, maintain, modify, repeal or revoke any of their respective program regulations or enabling legislation", see Agreement on the Harmonization and Integration of Cap-and-Trade Programs for Reducing Greenhouse Gas Emissions, supra note 41. In it, they have nonetheless committed to observe certain procedures enacted on a reciprocal basis in sub-national legislation, see generally Michael A. Mehling, Legal Frameworks for Linking National Emissions Trading Systems, in THE Oxford Handbook of International Climate Change Law 261 (Cinnamon P. Carlarne, Kevin R. Gray \& Richard G. Tarasofsky eds., 2016).

64 Steven Ferrey, Carbon Outlasts the Law: States Walk the Constitutional Line, 41 B.C. ENVTL. AFF. L. REV. 309 (2014); Darien Shanske, State-Level Carbon Taxes and the Dormant Commerce Clause: Can Formulary Apportionment Save the World? 18 CHAP. L. REV. 191 (2014); Shelley H. Welton, State Dynamism, Federal Constraints: Possible Constitutional Hurdles to Cross-Border Cap-and-Trade, 27 NAT. RESOURCES \& ENVT. 36 (2012).

65 Shear, supra note 59. 
contrario, that mere transfers are not conditional on Party status or approval ${ }^{66}-$ it is less clear whether that also means that both sides of a transfer must be Parties (or located within Parties). Should the U.S. withdraw from the Paris Agreement as announced, this question will be of significant relevance for the link between California, Ontario and Québec.

The ability to continue trading allowances across the link between these sub-national jurisdictions is not in question. Rather, the question is whether Canada - a Party to the Agreement - could then still claim allowances transferred from California - which would be located within a non-Party, the U.S. - towards achievement of the Canadian NDC. The wording of Article 6 provides no definitive answer to that question: although it mentions "Parties" throughout as the participants in cooperative approaches, including ITMO transfers, it does not expressly rule out involvement of non-Parties. Under international law, which is by default a permissive system, ${ }^{67}$ this could support an interpretation that Article 6 does not, in itself, prevent a Party like Canada from obtaining ITMOs from a non-Party and using these towards its NDC.

Even Article 6.3 and its requirement that "participating Parties" authorize such use would not necessarily rule out the foregoing interpretation, given that Canada would be the only "participating Party" to the transaction and its authorization could thus satisfy a permissive reading of Article 6.3. Indeed, if the authorization requirement in Article 6.3 primarily aims to protect Parties from uncoordinated transfers (for example, by a sub-national jurisdiction) that could jeopardize achievement of their NDCs, this permissive interpretation would also be supported by the ratio legis, or intent of the law: as a non-Party, the U.S. would not be held to achievement of an NDC, and thus would not require the protection afforded by an authorization requirement under Article 6.3. ${ }^{68}$

Still, because non-Parties would not be subject to the progressive ambition requirement and enhanced transparency framework of the Paris Agreement, among other treaty elements, such a permissive interpretation might meet with resistance by Parties concerned about transparency and the integrity of ITMOs. For now, the wording of Article 6.2 allows different interpretations, and it is unclear whether the guidance on operational details expected in 2018 can bring further clarification: this question goes beyond matters purely related to accounting, and may thus exceed the limited mandate to elaborate such guidance. ${ }^{69}$ Given the practical importance of this question in the event of a U.S. withdrawal, however, some form of clarification by Parties - whether through the guidance on Article 6.2, or an authoritative interpretation adopted at a session of the Conference of the Parties serving as the Meeting of the Parties to the Paris Agreement ("CMA"), would be helpful to provide legal certainty to market participants. But even if a more restrictive interpretation prevails, under which ITMOs transferred from a non-Party cannot be used towards NDC achievement, restricted linking - for example, through a gateway solution ${ }^{70}-$ might still allow for limited transfers and accounting toward NDCs.

66 This is also reflected in the wording of Article 6.1, which carefully avoids stating that voluntary cooperation as such requires any form of authorization, a concern of Parties already engaged (or planning to engage) in linking and other forms of bilateral or regional climate cooperation, see Andrew Howard, Voluntary Cooperation (Article 6), in The Paris Agreement on Climate Change: Analysis And Commentary 178 (Daniel Klein, María Pía Carazo, Meinhard Doelle, Jane Bulmer \& Andrew Higham eds., 2017).

67 See Case of the S.S. Lotus (France v. Turkey), Judgment, 1927 P.C.I.J. (ser. A) No. 10, at 45-47 (Sept. 7).

68 We thank Susan Biniaz for bringing this point to our attention.

69 See Adoption of the Paris Agreement, Decision 1/CP.21, in UNFCCC, Report of the Conference of the Parties on its Twenty-First Session, Addendum, at para. 36, FCCC/CP/2015/10/Add.1 (Jan. 29, 2016).

70 This refers to the approach considered historically for possible linkage between the EU ETS and a U.S. cap-andtrade system when the EU was an Annex B Party of the Kyoto Protocol and the U.S. was not. It would have 


\section{Heterogeneity of Targets}

There are two senses in which heterogeneity of targets may affect linkage. One is with regard to a given pair of linked policy instruments themselves; the other is with regard to the respective targets adopted by a pair of Parties to an international agreement, in particular, the Paris Climate Agreement.

Like policy instruments (see Section II.A), targets under an international agreement or a domestic instrument can differ in their degree of formality and normativity. They can be enacted in a more or less formal manner, and can be legally binding or merely aspirational in nature. Many Parties to the Paris Agreement have, for example, elaborated their NDCs and the mid- and longterm targets contained therein as programmatic or strategy documents, denying them the status and political resilience of formal legislation. Even where targets have been set out in binding executive orders or decisions, they afford only limited accountability, as the same or any future administration can choose to amend or annul the targets at any time; by contrast, formal legislation provides greater assurance that successive administrations will be bound to the targets enshrined therein unless and until the legislature chooses to formally enact changes. As with policy instruments, differences in the legal nature of targets do not have to preclude linking, although they can factor into the broader assessment of the risks and benefits arising from a link.

\section{Policy Instrument Targets}

In terms of the respective targets of a linked pair of policy instruments, relevant policies will tend to be expressed in the form of a GHG metric, such as metric tons of $\mathrm{CO}_{2}$-equivalent. Of these, a majority may use absolute targets, whether a mass-based aggregate cap in a cap-and-trade system, a specific tax rate in a carbon tax system, or mass-based individual limits in a regulatory system using a performance standard.

It is also possible that an aggregate or individual limit in a performance standard could be defined as a rate-based target (for example, tons of $\mathrm{CO}_{2}$ emissions per $\mathrm{kWh}$ of electricity output). In this case, it is straightforward to translate the rate-based target into mass-based units for purposes of trading (and linking) in a cap-and-trade system, and to translate it into mass-based units for purposes of linking in a performance standard system. If future vintages of emissions are involved in trading, such as through banking provisions, then anticipated output (ex ante projections) could presumably constitute the denominator, which itself could evolve over time.

If a regional, national, or sub-national policy were to use relative mass-based targets (for example, aggregate tons of emissions compared with anticipated Business-as-Usual ("BAU"), emissions), then it would be necessary to translate the aggregate relative target into simple mass terms for exchanges to take place, using ex ante quantitative estimates of BAU emissions.

Some targets may not be amenable to linking. China, for example, set a target of increasing its share of non-fossil fuels in primary energy consumption to "around $20 \%$ " by 2030 . One might

facilitated bidirectional transfers between both jurisdictions by stripping the Assigned Amount Unit (AAU) - the main accounting unit under the Kyoto Protocol - from EU allowances whenever the latter were transferred to the U.S., and would have restored such stripped AAUs to any units transferred from the U.S. to the EU, thereby ensuring consistency with the EU's accounting under the Kyoto Protocol, see Alexander Roßnagel, Evaluating Links between Emissions Trading Schemes: An Analytical Framework, 2 CARBON \& ClimATE L. REV. 394 (2008); Wolfgang Sterk, Marcel Braun, Constanze Haug, Katarina Korytarova \& Anja Scholten, Ready to Link Up? Implications of Design Differences for Linking Domestic Emissions Trading Schemes (Wuppertal Institute for Climate, Environment, and Energy JET-SET Working Paper I/06, 2006), https://perma.cc/HE5C-9VB4. 
imagine making some assumption about the fuels that are displaced and their carbon content to convert this target into a emissions target, but even then, it is not clear that China would want to link this particular target if the goal is to incentivize the growth of non-fossil fuel energy sectors in the country.

\section{NDC Targets under the Paris Agreement}

A key characteristic of the Paris Agreement's structure that led directly to the remarkably broad scope of achieved participation is the bottom-up structure of NDCs, and the fact that individual contributions are left to the discretion of respective Parties. ${ }^{71}$ This means that the specified contributions are not legally binding under international law, as clarified by Article 4.2 where it states that each Party shall prepare, communicate and maintain successive NDCs that it "intends to achieve". Accordingly, substantial flexibility was granted regarding both the form and content of such contributions. ${ }^{72}$ Consequently, the NDCs are exceptionally heterogeneous, including in regard to the ambition and the nature of quantitative targets. This is important for potential international linkages that would be tracked through ITMOs (to avoid double-counting of emissions reductions or other actions by Parties).

By the time the Paris Agreement came into force on November 4, 2016, 163 Intended Nationally Determined Contributions ("INDCs") had been submitted to the UNFCCC Secretariat by Parties to the Convention. Among the features of these INDCs and NDCs ${ }^{73}$ that are relevant for potential international linkages are: target type; reference year; target year; sectoral and geographic scope of coverage; GHGs covered; target conditionality; methodologies including for estimating global warming potential ("GWP") of GHGs; and intended use of market mechanisms (Table 2).

\section{a. Target Type}

Whereas under the Kyoto Protocol, all countries with emissions reduction responsibilities (largely the industrialized countries listed in Annex I of the Protocol) had quantified reduction objectives expressed relative to historic emission levels, under the Paris Agreement such mass-based absolute emission limits are only one of a number of types of targets employed. Of 163 submitted NDCs, 43 are in the form of Absolute GHG Targets. These account for $41 \%$ of global emissions (Table 2).

GHG Intensity Targets - emissions per unit of economic activity - characterize another 10 NDCs, accounting for 33\% of global emissions; and GHG Targets Relative to Business as Usual Emissions are found in 74 NDCs, which accounting for just $16 \%$ of global emissions. Thus, $90 \%$ of global emissions are covered by a total of 127 NDCs employing absolute, intensity, or relative targets. The remainder use a variety of other types of quantitative targets, including GHG emissions peaking in a specific year, degree of penetration of renewable energy sources, and

71 Daniel M. Bodansky, The Paris Climate Change Agreement: A New Hope? 110 AM. J. INT’L L. 269 (2016).

72 The Decision by the Conference of the Parties inviting submission of INDCs twice underscored that this invitation was "without prejudice to the legal nature of the contributions", see para. 2(b) of Further Advancing the Durban Platform, Decision 1/CP.19 in UNFCCC, Report of the Conference of the Parties on its Nineteenth Session, at 3 , FCCC/CP/2013/10/Add.1 (Jan. 31, 2014); likewise, the subsequent Decision detailing the type of information that could be included in the INDCs indicated that such inclusion was voluntary, see para. 14 of Lima Call for Climate Action, Decision 1/CP.20, in UNFCCC, Report of the Conference of the Parties on its Twentieth Session, at 2, FCCC/CP/2014/10/Add.1 (Feb. 2, 2015).

73 As Parties ratify the Agreement, their INDCs become NDCs. Hereafter, for convenience, we refer both to INDCs and NDCs as NDCs, except where the context requires differentiation for clarity. 
improvements in energy efficiency. ${ }^{74}$ With the exception of Turkey, all Annex I countries (plus 29 non-Annex I countries) use absolute GHG targets in their NDCs.

Linkage is most straightforward when both systems employ absolute (mass-based) targets. Linkage is also possible with jurisdictions expressing their aggregate targets as relative to BAU or in terms of carbon intensity of the economy, since exchanges can still be in mass terms, and the impacts on aggregate targets (such as through the ITMOs of Article 6) can be calculated by employing ex ante quantitative estimates of BAU emissions, which are often contained in the NDCs themselves, or by converting the intensity target to an absolute target once the relevant level of economic activity (such as Gross Domestic Product, "GDP") is known after the target year. ${ }^{75}$

Also, it should be noted that fully unconditional targets are employed by 34 NDCs, accounting for $68 \%$ of global emissions; conditional targets are used by 49 NDCs, accounting for $12 \%$ of emissions; and a mix of unconditional and conditional targets are found in 80 NDCs, accounting for $16 \%$ of global emissions. The conditional targets are most often specified as contingent upon international support being provided in the form of financial support or technology transfer.

\section{b. Reference and Target Years}

Of 163 submitted NDCs, 79 use (projected) BAU emissions as their base. Note that some countries may use a dynamic BAU baseline, whereby they update their BAU projections over time, whereas others may stick with their original BAU estimate (Table 2). With regard to dynamic baselines or with BAU baselines that are determined after the fact (for example, a BAU constructed in 2030), the effective ambition of the NDC targets may be driven by the uncertainty surrounding the BAU estimates, possibly making it difficult for sources in such countries to know whether they should be "buyers" or "sellers" under any international linkage.

On the other hand, 53 submissions have employed an historic base year or a fixed level of emissions, accounting for $74 \%$ of global emissions. This is extremely valuable for firms or monitors wishing to understand the stringency or precise level of the target and resulting shadow price of emissions. The specific base years or the specific emissions levels specified may differ among countries, but this need not impose any accounting problems for ITMOs in reconciling activities carried out between firms under linkage arrangements.

The vast majority of NDCs (117) have used 2030 as their target year. These NDCs account for over $70 \%$ of global emissions. A dozen other countries have identified some other year (2020, 2025,2035 , or 2050) as the time at which they will achieve their specified target. If a time-path of annual targets is not offered by an NDC, which is usually the case, then a simple linear (or some other) interpolation could be used for the purpose of accounting for necessary ITMO transfers. ${ }^{76}$

74 JAKob Graichen, MARTin CAMES \& LAMBERT SchNEIDER, CATEGORIZATION OF INDCS IN THE LiGHT OF ART. 6 OF THE PARIS AGREEMENT (2016), https://perma.cc/EAE9-5T9J.

75 For an example of a methodology to convert rate-based targets to mass-based targets, see U.S. Environmental Protection Agency (EPA), Translation of the Clean Power Plan Emission Rate-Based $\mathrm{CO}_{2}$ Goals to Mass-Based Equivalents (Technical Support Document, Nov. 2014), https://perma.cc/Q54V-SFX5.

76 Because guidance on Article 6.2 might not address how to account for ITMO transfers in non-target years, it will be up to Parties to voluntarily agree to a methodology consistent with whatever accounting rules the Parties do adopt. If two or more Parties want to facilitate linkage and count transferred ITMOs towards NDC achievement, they should also be incentivized to agree to such rules. 
Linkage between systems with different target years should not present a problem, but accounting rules will need to be clear on transfer of ITMOs between such linked systems. ${ }^{77}$

\section{c. Sectoral and Geographic Coverage}

Some 71 NDCs, which account for $86 \%$ of global emissions, are economy-wide in their coverage. The other 92 NDCs include the energy sector, frequently in combination with some limited set of other sectors. Nearly all NDCs cover the entire territory of respective countries.

Linkages between climate policies in different jurisdictions need not be affected by differences in sectoral or geographic coverage. However, accounting for executed international transfers through ITMOs can be challenging when limited sectors or geographic areas within countries are covered by their respective policies. The challenge - indeed, the problem - arises when there is significant emissions leakage from regulated to unregulated sectors or from regulated to unregulated geographic areas. Then, what appears to be an emission reduction from a particular country may be less than it appears to be, because of a consequent emissions increase in the unregulated sector/area.

\section{d. GHG Coverage}

The Paris Agreement addresses reductions in all GHGs not controlled by the Montreal Protocol, including: carbon dioxide $\left(\mathrm{CO}_{2}\right)$; methane $\left(\mathrm{CH}_{4}\right)$; nitrous oxide $\left(\mathrm{N}_{2} \mathrm{O}\right)$; hydrofluorocarbons (HFCs); perfluorocarbons (PFCs); sulphur hexafluoride $\left(\mathrm{SF}_{6}\right)$; and nitrogen trifluoride $\left(\mathrm{NF}_{3}\right)$. It is up to each Party, however, which GHGs to include in its NDC. Presumably all NDCs include $\mathrm{CO}_{2}$ emissions, although 23 of the 163 submitted (accounting for 6\% of global emissions) do not specify the gases covered. Thirty-nine NDCs explicitly cover all GHGs, accounting for 57\% of global emissions, using one of two Kyoto Protocol lists. ${ }^{78}$ Another 85 specify $\mathrm{CO}_{2}$ plus some other GHGs, and 16 specify coverage of $\mathrm{CO}_{2}$ only.

As with limited sectoral and geographic scope (see Section II.C.2.c, above), there is not necessarily an issue here for linkage per se, but proper accounting for executed international transfers through ITMOs could be problematic if there is significant leakage from regulated to unregulated GHGs. However, leakage across GHGs would seem to be much less likely than sectoral or geographic leakage.

\section{e. Global Warming Potential Values}

When NDCs include more than a single GHG $\left(\mathrm{CO}_{2}\right)$, then calculations are required to convert emissions and emissions reductions of various other GHGs to a common unit, $\mathrm{CO}_{2}$ equivalent. Such calculations involve not only information regarding the impacts of specific GHGs on radiative forcing, but also an assumed time period for the calculation, since the GHGs display dramatically different lag times in the atmosphere. The results of such estimates are the GWP of each GHG, which also depends upon existing concentrations of these gases in the atmosphere.

The Intergovernmental Panel on Climate Change ("IPCC") has periodically updated the estimated GWP of each of the GHGs. More than half of country submissions (82 NDCs accounting for $42 \%$ of global emissions) do not specify what GWP values are used, whereas 33 NDCs

77 Organisation for Economic Co-operation and Development (OECD), Workshop Summary and Background Document: Workshop on "Corresponding Adjustment" as Part of Article 6 Accounting (Feb. 20, 2017), https://perma.cc/M95V-BQ9H.

78 In the Kyoto Protocol's first commitment period, the first six GHGs were included. In the second commitment period, all seven are covered. Under the UNFCCC, GHGs covered by the Vienna Convention for the Protection of the Ozone Layer and its Montreal Protocol are excluded. 
(covering 45\% of global emissions) rely on GWPs from the Fourth Assessment Report of the IPCC (AR4), 45 NDCs (covering 5\% of emissions) rely on AR2 estimates, and just 3 NDCs (covering about $4 \%$ of global emissions) state their reliance on the most recent AR5 values. In principle, the use of different assumed GWPs by different NDCs can render more difficult the accounting exercise to be carried out for ITMOs.

\section{f. Heterogeneity of NDCs of Key Countries}

Given that the twenty largest economies ("G20") - counting the European Union as one - account for approximately $80 \%$ of global GHG emissions, it is reasonable to focus on that subset of the 195 Parties of the Paris Agreement when thinking about the challenges posed by heterogeneity across NDCs (Table 3). Doing so reveals a much less challenging picture than emerges when reviewing the full set of 163 NDCs. Among the G20 countries, all but one (Saudi Arabia) employ absolute, relative, or intensity targets; nearly all cover all sectors of their respective economies, as well as all GHGs; and only India and Saudi Arabia utilize pure conditionality in their NDCs. ${ }^{79}$

\section{ILLUSTRATIVE CASES OF POTENTIAL CLIMATE POLICY LINKAGES}

Here we examine the feasibility of some illustrative cases of potential international linkage of climate policies in ways that would be consistent with the Paris Agreement, taking into account the three categories and two sub-categories of heterogeneity elaborated in Section II: policy instrument, jurisdiction (distinguishing level of jurisdiction and status (Party or non-Party) under the Paris Agreement), and target (distinguishing policy target and NDC target) (Table 4).

As discussed above, the major options for policy instruments are carbon tax, cap-and-trade, performance standard, and technology standard. Jurisdictions are regional (the EU), national, or sub-national (mainly states and provinces). Status (in relation to the Paris Agreement) is either Party or non-Party. Policy targets (of a given carbon tax or cap-and-trade system, for example) include absolute mass-based, relative (to BAU) mass-based, and carbon intensity; and NDC targets include absolute GHG, relative GHG, GHG intensity, and non-GHG targets.

We consider five illustrative cases of potential linkages, some of which map approximately to existing examples, but most of which are included to span some of the potentially important possibilities: ${ }^{80}$

(1) linkage between two mass-based cap-and-trade systems, both at the national level, with both countries Parties to the Paris Agreement using absolute GHG targets in their respective NDCs;

(2) linkage between a mass-based carbon tax and a mass-based cap-and-trade system, both at the sub-national level, and both jurisdictions located within countries that are Paris Agreement Parties with absolute GHG NDC targets;

79 Some countries have multiple targets. As noted above, China's NDC includes a non-fossil fuel penetration target. But it is still the case that it has a GHG target that presumably would be the focus of any linking activity.

80 Given the greater relevance for linking, all cases involve policy instruments (and targets) that are based on some form of GHG metric (such as metric tons of $\mathrm{CO}_{2}$ equivalent), although, as noted above, policies based on other metrics - such as a specific volume or share of renewable energy - could also feature in a link (potentially requiring conversion into a fungible metric when metrics are not identical). Also, accounting for transfers in emissions inventories will necessitate translation into a GHG metric. 
(3) linkage between two mass-based cap-and-trade systems, one regional and one subnational, with the regional system a Party of the Paris Agreement and the subnational system in a non-Party country, with an absolute GHG NDC target in the former;

(4) linkage between a rate-based performance standard with a mass-based cap-andtrade system, both at the national level, both Parties of the Paris Agreement, with an absolute GHG NDC target and a relative GHG NDC target, respectively; and linkage between two mass-based carbon taxes, both at the national level in nonParty countries (without NDCs).

\section{A. Case 1: Two National Mass-Based Cap-and-Trade Systems, Paris Agreement Parties, Absolute NDC Targets}

This is the most straightforward case for international climate policy linkage, and one reason we include it is to provide a convenient base case for comparison. With two countries, both of which are Parties to the Paris Agreement and employ absolute mass-based GHG targets in their NDCs, ${ }^{\mathbf{8 1}}$ the prerequisites for straightforward linkage are met. Furthermore, the fact that the pair of countries both use national mass-based cap-and-trade systems makes this hypothetical case ideally suited for linkage. An illustration of this case would be - in principle - linkage between New Zealand and Switzerland.

Even in this simplest case, however, concerns might be expressed about the effects of such a link. ${ }^{82}$ Fortunately, the vast majority of these concerns are actually not impediments to linkage. ${ }^{83}$ Most are not concerns about linkage per se, but broader concerns about design alignment (for its own sake). Also, note that a number of these concerns are not specific to cap-and-trade systems; they may arise with other policy instruments as well.

First of all, concerns are often expressed regarding differences in allowance prices between two systems that are candidates for linking. Of course, if there is no difference in the allowance price between two jurisdictions, then there is little to be gained on cost-effectiveness grounds through linkage, since the identical allowance prices indicate that marginal abatement costs are already equated, and hence overall reductions will be achieved cost-effectively. As the difference between allowance prices increases, the potential economic benefits of linkage increase, with greater gains in cost-effectiveness.

However, as allowance prices converge, lower or higher prices in the two linked systems can impair other policy objectives, such as price-induced technological change. Furthermore, an allowance price increase in a system prone to emissions leakage can increase global emissions. More broadly, allowance price changes can induce increases or decreases in co-benefits as emissions reductions are re-allocated. In any event, while price convergence will produce aggregate net benefits (cost savings), there are distributional implications since there will be both

81 Examples of national Paris Agreement Parties with absolute, mass-based NDC targets include: Australia, Brazil, Canada, Japan, Russia, and - for the time being - the United States (Table 3).

82 Green, supra note 15.

83 Judson Jaffe and Robert N. Stavins, Linking a U.S. Cap-and-Trade System for Greenhouse Gas Emissions: Opportunities, Implications, and Challenges (AEI-Brookings Joint Center for Regulatory Studies Working Papers 08-01, Jan. 2008), https://perma.cc/PX5C-YAMJ; Jaffe et al., supra note 13. 
winners and losers among compliance entities in both systems, as we examined in Section I, above. Likewise, international capital flows can be induced by linkage. Because exchanges under a linkage arrangement are voluntary, these capital flows necessarily are beneficial to the entities involved in the trading. However, there may be political objections to potentially large capital flows. $^{84}$

A second area of frequently expressed concern relates to the scope of sectoral coverage. However, linked systems need not cover the same sectors, although a single-sector system, for example, is automatically linked with all sectors covered by the other system. Still, the scope of coverage can affect differences in allowance prices (taking us back to the first concern, above). An example is a cap and trade system that covers one sector with high marginal abatement costs linked with a cap and trade system in another country that covers several sectors - including the sector covered in the first country's system. If the additional sectors included in the second country's system have greater scope for emissions reduction at low cost, then linking the first country's system with the second country's system gives firms in the former country access to low cost allowances that can be used in place of high cost abatement options in their own country.

Third, differences in the point of regulation - ranging from a fully upstream system (that regulates the carbon content of the three fossil fuels as they enter the economy) to a fully downstream system (that regulates $\mathrm{CO}_{2}$ emissions) - give rise to legitimate concerns about possible double-counting of emissions when fuel in an upstream system is used in a downstream system. However, this issue arises whether or not the systems are linked. Assume country A measures emissions upstream. Fuel extracted and exported to country B which measures emissions on combustion would be counted both by country A and B. This is a more fundamental issue about NDC coverage. Presumably NDCs are focused on emissions related to domestic consumption in which case the solution is simple: any upstream system should exclude exported fossil fuel from allowance requirements (or, more generally, from coverage under the NDC).

Fourth, concerns can arise (although not in our Case 1) over differences in the nature of the caps of two systems, such as between an absolute cap and an intensity cap (per unit of GDP or other output measure). If a link increases economic activity or output, then total emissions can increase. But it is also possible that a link cuts economic activity/output, and thereby decreases total emissions. Fifth, concerns may arise among some firms over differences in the point (in the economy) of the allocation of allowances (again, upstream versus downstream, for example). These differences need not be any barrier to linkage, although this will affect the distributional implications of the policies in both jurisdictions.

Sixth, concerns may arise over potential differences in the nature of the allocation in the two jurisdictions, for example, auctioning versus free distribution. Under typical conditions, the method of allocation has no effect on the allowance price (opportunity cost) in the two systems, but will have distributional implications within both jurisdictions. When an output-based updating allocation is used within one of the systems to address competitiveness concerns, however, the result can be that total costs will increase.

Seventh, an important concern is the possibility of significant differences between the two jurisdictions' systems in terms of monitoring, reporting, and enforcement provisions. Lax enforcement in one country can propagate through linkage and trading to increased emissions in both systems. Eighth and finally, different cost-containment provisions may be found in two systems that are candidates for linking: offsets, banking, and price floor/ceiling. The concern is

84 If differences in allowance prices and resulting capital flows between systems are perceived to result largely from differences in the stringency of their caps, there is more likely to be political resistance to the capital flows, Jaffe et al., supra note 83 . 
that once linkage occurs and trading commences, there is automatic propagation of these costcontainment elements from one system to the other.

None of these potential concerns are impediments in and of themselves to the prospects for international policy linkage, but they are issues to keep in mind. By allowing Parties to operationalize linkages through the transfer of ITMOs, the Paris Agreement's Article 6.2 and future guidance on its implementation can provide a credible accounting framework for the national aggregation of the firm-firm (source-source) international trading that would occur under this country-country linkage.

\section{B. Case 2: Two Sub-National Systems (Carbon Tax and Cap-and-Trade), both in Paris Agreement Parties with Absolute NDC Targets}

This second case differs from the first case in two ways. First, both of the linkage candidates are sub-national policies, and, second, here one of the two is a carbon tax, while the other is a capand-trade system. Both jurisdictions are located within Parties to the Paris Agreement (which both employ absolute NDC targets). This situation would correspond, for example, to a linkage arrangement between the city of Tokyo (which has a cap-and-trade system) and the Canadian province of British Columbia (which has a carbon tax).

This second linkage case is feasible, although not as simple as Case $1 .{ }^{85}$ As explained above (see Section II.A.2), the policy-instrument heterogeneity could be addressed through the use of Emission Tax Payment Credits (ETPCs). In the carbon-tax jurisdiction, firms could pay taxes at a higher level than they owe based on their emissions, and then sell certified ETPCs to firms operating in the cap-and-trade jurisdiction. Within the cap-and-trade program, firms could use ETPCs as they would the equivalent quantity of allowances for purposes of compliance. Firms in the cap-and-trade jurisdiction could sell allowances to firms required to pay a carbon tax in the other jurisdiction, allowing the purchasing firm to reduce its tax obligation by the amount of allowances it submits for retirement. ${ }^{86}$ The trading would be on a mass-based equivalence, that is, the tax liability for one ton of GHG emissions would be offset by surrendering one ton of allowances.

Note that Case 1 partly converges to this case where one of the cap-and-trade systems in Case 1 has a very narrow price collar. The previous issues of design heterogeneity apply here, plus some special considerations. Unrestricted linkage will turn the cap-and-trade system into an implicit carbon tax system, which introduces two concerns. First, the absolute limit (cap) on emissions in the cap-and-trade jurisdiction is broken as a result of the link with the tax jurisdiction. Second, the tax revenues in the taxing jurisdiction can be reduced as a result of the link.

As outlined earlier (Section II.B.1), because the two participants to the link in this case are sub-national jurisdictions, they cannot currently be Parties to the Paris Agreement. That said, they are both located within Parties with absolute GHG targets in their respective NDCs. In order to ensure consistency with Article 6.3 of the Paris Agreement, the use of ITMOs to achieve an NDC needs to be authorized by the participating Parties. Each Party will also need to account for the transfers by way of a national aggregation of the firm-firm international exchanges under the link. For the carbon tax and any ETPCs issued under it, such accounting will involve a calculation of the emission reductions achieved through overpayment of the tax liability. As for the cap-and-

85 Many of the concerns considered in Case 1 also apply in this second case and in the subsequent cases, but for purposes of brevity we do not repeat our analysis from the discussion of Case 1.

86 Metcalf et al., supra note 21. 
trade system, units are already commonly denominated in absolute amounts of GHG emissions, making this task easier. Ensuring that the accounting principles in the Paris Agreement and any subsequent guidance are observed will be up to the national reporting systems of the two Parties, as well as any registry systems used to track unit holdings, transfers, and cancellations.

\section{Case 3: Two Cap-and-Trade Systems, One a Regional Party of the Paris Agreement (with an Absolute NDC Target) and one a Sub-National System in a Non-Party}

This third case of potential linkage represents greater diversity than the first two cases. Here, one of the policies being linked is a mass-based cap-and-trade system in a regional economic integration organization that is a Party of the Paris Agreement and that has an absolute GHG NDC target. This corresponds to the European Union Emissions Trading System ("EU ETS"). The other policy is also a mass-based cap-and-trade system but is being used by a sub-national jurisdiction that is located in a country that is not a Party to the Paris Agreement. This would correspond to California's economy-wide cap-and-trade system when and if the United States completes its withdrawal from the Paris Agreement in November, 2020.

The fact that one cap-and-trade system is multinational and the other cap-and-trade system is sub-national presents no fundamental problems from a physical or economic perspective. Likewise, as previously discussed, the fact that their scopes and sectoral coverage differ is not an impediment to effective linkage. It bears noting that both jurisdictions mentioned as examples for this case, the EU and California, have substantive linking conditions spelled out in the legislation setting up their cap-and-trade systems. For the EU, linking its cap-and-trade system to jurisdictions other than those with quantitative targets under the Kyoto Protocol is only possible if these have "compatible mandatory greenhouse gas emissions trading systems with absolute emissions caps". ${ }^{87}$ Likewise, California requires that any linking partner have "adopted program requirements for greenhouse gas reductions ... that are equivalent to or stricter than those required" in California. ${ }^{88}$ Depending on how the terms "compatible" and "stricter" are interpreted, both conditions could, in principle, be met if the EU and California chose to link.

A more significant challenge arising from this case relates to the divergent status of the two jurisdictions under the Paris Agreement. As discussed earlier (Section II.B.2), the wording of Article 6 does not provide certainty on whether and how ITMOs transferred from the non-Party might be used by the Party towards achievement of its NDC. Pending further clarification of the sparse wording of Article 6 through forthcoming guidance on its implementation, the EU could encounter difficulties if it sought credit towards achievement of its NDC for emissions reductions transferred from California, should the U.S. follow through with its announced withdrawal from the Paris Agreement. Different possible interpretations of Article 6.2 and 6.3 will result in different answers to this question, and Section II.B.2 already examined the alternative interpretations, as well as some of the main arguments supporting each option. Unconstrained by the need to adhere to international accounting rules, meanwhile, California would have greater latitude in how it treats any such transactions, and could unilaterally decide whether and how to recognize EU allowances for domestic compliance and accounting purposes.

87 Art. 25 (1a) of Directive 2003/87/EC of the European Parliament and of the Council of 13 October 2003 Establishing a Scheme for Greenhouse Gas Emission Allowance Trading within the Community and Amending Council Directive 96/61/EC, 2003 O.J. (L 275) 32, as amended by Directive 2009/29/EC of the European Parliament and of the Council of 23 April 2009 amending Directive 2003/87/EC so as to Improve and Extend the Greenhouse Gas Emission Allowance Trading Scheme of the Community, 2009 O.J. (L 140) 63.

88

Calif. S.B. 1018, Public Resources, § 12894 (f) (1) and (3) (2011-2012). 


\section{Case 4: National Performance Standard with Absolute GHG NDC Target and Mass- Based National Cap-and-Trade with Relative GHG Target, both Parties to the Paris}

Agreement

This departs from the three previous cases in several ways, and corresponds to a potential linkage between Japan's various national performance standards for appliances, vehicles and building (all under an absolute GHG NDC target) and South Korea's national mass-based cap-and-trade system (under a GHG NDC target that is relative to BAU emissions).

First, this case features the combination of a performance standard in one country with a cap-and-trade system in another. As discussed above, this need not be an impediment to linkage. If the performance standard is a mass-based quantity standard, firms can buy allowances from the cap-and-trade system (or ETPCs from a carbon tax system) to meet required reductions (or firms can achieve reductions in excess of the regulatory minimum and sell additional reductions as ERCs). If the performance-standard system is an emissions rate-based standard, actions under the system can still be translated into mass-based outcomes, which can then form the basis of any trades. Specifically, rate-based (intensity) standards can be translated into quantity standards at the source or firm level (per total output, total sales, or whatever denominator the regulation prescribes), which ultimately allows for linkage.

Another aspect of this case that differs from the previous cases is the heterogeneity in the types of NDC targets, with the performance-standard country using an absolute GHG target and the cap-and-trade country using a relative (to BAU) GHG target. Linkage is possible with jurisdictions expressing their aggregate targets as relative to BAU, because exchanges can be in mass terms, and the impacts on aggregate targets (through the ITMOs of Article 6) can be calculated by employing ex ante quantitative estimates of BAU emissions. Most NDCs that specify a target relative to BAU also set out a BAU projection for the target year, allowing direct conversion of the national target into absolute mass-based terms. The same issues arise here as discussed above around the degree to which the BAU target is fixed or subject to revision.

\section{E. Case 5: Two National Mass-Based Carbon Tax Instruments in Non-Parties of the Paris Agreement}

This final case corresponds to what some analysts have proposed as an alternative approach to international climate policy cooperation, which they consider superior to the approaches taken by the UNFCCC and the Paris Agreement. It also may correspond to what some policy-makers consider a reasonable fallback position if the Paris Agreement coalition were to collapse. Here we have a pair of national mass-based carbon tax systems, where neither country is a Party to the Paris Agreement.

In the most direct manifestation of this, a pair or - as proposed by Nordhaus ${ }^{89}$ - a set of countries would each put in place a domestic carbon tax. Each participating country would keep for itself the revenue generated, and simultaneously institute significant border adjustments against imports from non-participants, in order to provide incentives for countries to participate in this "club" and thereby overcome the free-rider problem of climate change protection. A parallel

89

Nordhaus, supra note 20. 
approach featuring domestic cap-and-trade systems rather than carbon taxes could be similar, depending upon its design. ${ }^{90}$ This is an example of soft linkage as described earlier.

Whether such systems would be likely to achieve the same, lesser, or greater degrees of aggregate emissions reductions as will cooperation under the Paris Agreement is an open question, well outside the scope of our analysis. But, within the scope of our investigation, it is clear that the international linkage elements of such an approach would be feasible, as with our simplest example, the benchmark of Case 1. No linkage beyond an agreement on a carbon price would be needed, although past experience has shown that international cooperation on tax harmonization is challenging.

\section{COMMON THREADS, POLICY IMPLICATIONS, AND PENDING QUESTIONS}

Most features of heterogeneity - including those associated with heterogeneous policy instruments, heterogeneous jurisdictions, and heterogeneous targets - do not present insurmountable obstacles to linkage. However, some of these characteristics present challenges and indicate the need for specific accounting guidance if linkage is to include the use of transferred ITMOs towards achievement of NDCs, as provided for in Article 6.2 and 6.3 of the Paris Agreement. With their sparse wording and remaining ambiguities, these PA provisions reflect a compromise that intentionally does not address important questions of implementation. Parties have therefore included a mandate in Article 6.2, charging the CMA with adoption of relevant guidance; this guidance will, in turn, be informed by a recommendation developed by the Subsidiary Body for Scientific and Technological Advice (SBSTA) under the decision accompanying the Paris Agreement. ${ }^{91}$

The following sections of this paper consider issues that could arise in such guidance, the extent to which these issues are included in the mandate to elaborate guidance, and the implications of both questions for linkage. ${ }^{92}$ Pursuant to Article 6.2, the mandate to adopt guidance clearly extends to robust accounting, including avoidance of double counting, when using transferred ITMOs towards NDC achievement (Section IV.A, below). It is less clear, however, whether such guidance can also stipulate material provisions that go beyond accounting issues, for instance on matters of environmental integrity and governance (Section IV.B, below). Section IV.C concludes with thoughts on the outlook for heterogeneous linkage that will be consistent with the Paris Agreement.

\section{A. Accounting Treatment of ITMO Transfers and Use}

Robust accounting methods will be needed to prevent double-counting of emission reductions and to ensure that the timing (vintage) of emissions reductions and of respective ITMO transfers are correctly accounted for. The targets set out in NDCs display substantial heterogeneity with regard

90 Nathaniel O. Keohane, Carol A. Petsonk \& Alex G. Hanafi, Toward a Club of Carbon Markets, 144 CLIMATIC CHANGE 81 (2017).

91 See Article 6.2 of the Paris Agreement and Adoption of the Paris Agreement, Decision 1/CP.21, supra note 69, at para. 36.

92 See also International Emissions Trading Association (IETA), A Vision for the Market Provisions of the Paris Agreement (May 2017), https://perma.cc/VUZ3-6JPS. 
to target type, reference and target years, sectoral and gas coverage, and GWP assumptions. Accounting for emissions and ITMO transfers under the Paris Agreement will therefore present much greater challenges than under the Kyoto Protocol, where all commitments consisted of absolute emission budgets with the same target years and generally the same reference year. ${ }^{93}$ Acknowledging this challenge, Parties included a clear mandate in Article 6.2 to adopt guidance on robust accounting and avoidance of double counting for cooperative approaches that involve the use of ITMOs towards NDC achievement.

A starting point for guidance on accounting is the fact that, absent some form of accounting framework, ITMOs create the potential for double counting and thus for greater GHG emissions than would occur in the absence of ITMO transfers. ${ }^{94}$ Avoiding double-counting of emission reductions, whether through double issuance, double claiming, or double use, can therefore be expected to feature centrally in the guidance on Article 6.2. A related operational question concerns how Parties make adjustments for emissions or reductions covered by their NDCs when using ITMOs, the so-called "corresponding adjustments" referenced in the decision that accompanied the Paris Agreement. ${ }^{95}$ Two alternative approaches have been identified to effect this adjustment: an adjustment based on inventory emissions, in which ITMOs are added or subtracted to reach an adjusted emissions level; or an adjustment based on the NDC target level, in which ITMOs are added or subtracted to reach an adjusted target level. ${ }^{96}$ While neither approach is necessarily superior, uniformity across approaches will be important to avoid inconsistencies.

Additional issues that may arise when accounting for ITMO transfers under Article 6 include: how to quantify ITMOs (whether through carbon taxes, cap-and-trade instruments, performance standards, or other domestic policy instruments); how to account for differences in assumed GWP; and heterogeneous base years as well as different vintages of targets and outcomes. ${ }^{97}$ Guidance on Article 6.2 could give attention to these issues, and also address the accounting implications of different types of targets, such as absolute and relative GHG targets, ${ }^{98}$ as well as the metrics used to account for ITMOs - will there be a single common metric, such as

93 JIKO, Confrontation or Convergence? Surveying Submissions on Article 6 of the Paris Agreement, CARBON MECHANISMS REVIEW 4 (Nov.-Dec. 2016), https://perma.cc/9QXG-UU2U.

94 LAMBERT SCHNEIDER ET AL., ENVIRONMENTAL INTEGRITY UNDER ARTICLE 6 OF THE PARIS AGREEMENT (2017), https://perma.cc/S75X-NKUM.

95 See Adoption of the Paris Agreement, Decision 1/CP.21, supra note 69, at para. 36.

96 Organisation for Economic Co-operation and Development, supra note 77.

97 LAMBERT SCHNEIDER ET AL., ROBUST ACCOUNTING OF INTERNATIONAL TRANSFERS UNDER ARTICLE 6 OF THE PARIS AgreEMENT: PRELIMINARY FInDNGS (2016), https://perma.cc/59TQ-3SJV; Howard, supra note 66. Heterogeneous historic base years in NDCs do not impose accounting problems for ITMOs in reconciling activities carried out between firms under linkage arrangements, but differences in target years will need to be recognized and reconciled through a linear (or other) normalization for calculating appropriate accounting of ITMO transfers (if full time-paths of targets are not offered by the respective NDCs), see Organisation for Economic Co-operation and Development, supra note 77.

98 Absolute (mass-based) targets may require the least scrutiny, but exchanges between jurisdictions expressing their aggregate targets as relative to BAU or in terms of carbon intensity of the economy are also feasible. This is because the exchanges themselves can still be in mass terms, and hence the impacts on aggregate targets (through ITMOs) can be calculated by employing ex ante quantitative estimates of BAU emissions, or by converting the intensity target to an absolute target once the relevant level of GDP is known, see Nicolas Kreibich \& Wolfgang Obergassel, Carbon Markets after Paris: How to Account for the Transfer of Mitigation Results? (JIKO Policy Paper No. 01/2016, Jan. 2016), https://perma.cc/7HWX-VEX9. 
tons of $\mathrm{CO}_{2}$ equivalent, or will there be multiple metrics, including, for example, other measures such as installed capacity of renewable power? ${ }^{99}$

Broader questions related to NDCs and ITMOs that nonetheless have a bearing on accounting under Article 6.2 include the nature of NDC targets, and whether these are to be treated as strict numerical targets that need to be precisely achieved; the nature and scope of ITMOs, which are hardly defined, let alone fully described in the Agreement and accompanying decisions; tracking of the transfer and use of ITMOs via a registry; and finally, given different potential interpretations of Article 6.2 and 6.3, whether transfers to or from non-Parties (or sub-national jurisdictions therein) are possible, and how they should be accounted for.

Uniform guidance on these issues could arguably help ensure consistency across ITMO transfers, and afford greater certainty and predictability to Parties engaged in voluntary cooperation. As a result, guidance on these issues could potentially facilitate and promote expanded use of linkage between Parties to the Paris Agreement. Whether some or all of these issues can be addressed in the guidance on Article 6.2 is doubtful, however. It is important to recognize that the mandate for guidance on Article 6.2 does not expressly mention these issues, and any attempt to address them with centralized standards will therefore be likely to invite opposition and criticism from Parties that the CMA is exceeding its mandate and violating the decentralized spirit of the Paris Agreement. Indeed, some of the issues mentioned above, such as a registry infrastructure to track ITMO transfers, can also be dealt with at the domestic level, and it is therefore a legitimate question whether these issues necessarily have to be included in Article 6.2 guidance, or can equally and perhaps more efficiently be addressed by individual Parties.

That said, to satisfy the mandate in Article 6.2, the CMA must adopt guidance that helps ensure robust accounting of ITMO use towards NDC achievement, and avoidance of double counting. As the CMA and SBSTA consider what this mandate entails, they may also decide to address some of the other issues mentioned above.

\section{B. Potential Further Issues for Attention}

Beyond issues related to accounting and avoidance of double counting, Parties have also suggested a number of further issues for inclusion or clarification in guidance on Article 6.2. Some Parties, for example, have argued in favor of ensuring that a transferred ITMO corresponds to actual emission reductions. ${ }^{100}$ Other issues identified (but not agreed) by individual Parties for potential inclusion in guidance on Article 6.2 include: ${ }^{101}$ overarching issues, principles, and considerations; definitions; governance; supervision; accountability; the role of ambition; environmental integrity;

99 This relates to a broader question of whether ITMOs will be, in effect, a single unit of compliance, or whether there will be various types. Among Parties that have expressed a preference on this issue, a majority seems to favor expressing ITMOs in tons of $\mathrm{CO}_{2}$ equivalent, see JIKO, supra note 93. Still, that leaves room for different types of transferable units, which might be allowances, credits (which would include offset credits, but also could include ERCs and ETPCs), or target/inventory adjustments.

100 See, for example, Government of Brazil, Views of Brazil on the Guidance Referred to in Article 6, Paragraph 2, of the Paris Agreement (Mar. 2017), https://perma.cc/M9CG-B776.

101 JIKO, supra note 93; Andrei Marcu, Article 6 of the Paris Agreement: Reflections on Party Submissions before Marrakech (International Centre for Trade and Sustainable Development Background Paper, March 2017), https://perma.cc/V9LE-KBS3; UNFCCC, Informal Information Note by the Co-Facilitators: SBSTA 46 Agenda Item 10 (a) - Guidance on Cooperative Approaches referred to in Article 6, Paragraph 2, of the Paris Agreement (17 May 2017), https://perma.cc/LDP5-XPBA. 
promoting sustainable development; and transparency. ${ }^{102}$ As noted, however, these issues go beyond the mandate of the CMA under Article 6.2, and may therefore not find their reflection in the final guidance scheduled for adoption by Parties in December 2018.

Many of these issues relate to the environmental implications of ITMO use, and how to safeguard or strengthen environmental integrity and ambition. Four specific areas of potential concern can be identified: First, in situations where a country that is proposing a transfer has an NDC target that is less stringent than its BAU emissions, and hence has a so-called "hot air" target, ITMOs could undermine the integrity of the transferee's NDC. ${ }^{103}$ Second, situations where ITMO transfers involve NDCs with limited sectoral or geographic coverage create the potential for leakage, and therefore should receive special attention if and only if significant leakage from regulated to unregulated sectors or geographic areas is anticipated. Third, the same holds true for GHG coverage, but it is less likely that there would be significant anticipated leakage from regulated to unregulated GHGs. And fourth, if ITMO transfers are possible from non-Parties or from sectors and activities that are not covered by an NDC, the ability to engage in such transactions - particularly if the transferred ITMOs can be used towards NDC achievement - could foster an incentive to refrain from becoming a Party or from including such activities and sectors in the scope of the NDC. That, in turn, would work against the goal of moving towards progressively more ambitious NDCs with greater sectoral and geographic coverage.

While some Parties are likely to seek inclusion of integrity and ambition criteria in the guidance on Article 6.2, and can point to the references in Article 6 to environmental integrity, transparency, governance, and sustainable development, the current mandate in the Paris Agreement and the accompanying decision do not give reason to expect they will succeed. Parties do have the option of adopting, by consensus, an authoritative interpretation of Article 6.2 that supports a more expansive mandate, but such a consensus - if it exists - would arguably have already found its reflection in the Paris Agreement itself. Given that Parties instead rejected any form of centralized governance architecture, ${ }^{104}$ it is unrealistic to expect guidance on much beyond key accounting issues. In the end, the limited mandate afforded to the CMA will likely mean that jurisdictions retain ample flexibility regarding whether and how to engage in voluntary cooperation. $^{105}$

\section{The Outlook for Heterogeneous Linkage Consistent with the Paris Agreement}

As they negotiate the work program on implementation of the Paris Agreement, Parties have an opportunity to define clear and consistent guidance for accounting of emissions transfers under Article 6. During the latest discussions in Bonn in November 2017, Parties signaled agreement on the need to offer at least minimal guidance on how to account for transfers of ITMOs, but expressed

102 It bears noting that the "informal information notice" contained in UNFCCC, supra note 102, repeatedly emphasizes that it has no official standing and is "a non-exhaustive and unstructured list of elements" and "does not represent agreement" nor is "in any way a suggested basis [or] forecast of any future direction of work." In other words, Parties are still far from reaching agreement on these elements or a sense of prioritization.

103 Whereas the full set of NDC targets under the Paris Agreement would bring about a significant decrease in global emissions in 2030 relative to $\mathrm{BAU}$, one analysis estimates that more than $65 \%$ of those emissions reductions could be negated if all "hot air" from NDCs that are less stringent than BAU were transferred internationally to other participating countries, see SCHNEIDER et al., supra note 94.

105 Andrei Marcu, Issues for Discussion to Operationalise Article 6 of the Paris Agreement (International Centre for Trade and Sustainable Development Background Paper, March 2017), https://perma.cc/R9WR-AZC4. 
widely differing views on broader principles and technical details. ${ }^{106}$ Currently, all options remain on the table, and negotiations in Bonn merely resulted in a decision to narrow down areas of convergence and elaborate "draft elements of guidance" during the course of the following year. ${ }^{107}$ Any issues that elude a consensus decision will be omitted from guidance and left to the discretion of individual Parties.

If they can set aside political differences and agree on a robust accounting framework for ITMO transfers and use, Parties will create an enabling context for strengthened linkage of climate policies across jurisdictions. Just as the CDM created an offset crediting framework that was subsequently recognized in a number of domestic cap-and-trade systems, resulting in several indirect links, a minimum set of harmonized accounting rules adopted in guidance on Article 6.2 of the Paris Agreement could form the basis of a common accounting framework for emission transfers. That, in turn, could help ensure the fungibility of units and promote the transparency and credibility of domestic policy efforts, making it easier for jurisdictions to enter into linking arrangements. ${ }^{108}$

If guidance extends beyond a shared core of accounting rules, the opposite could become true: restrictive quality or ambition requirements might inadvertently impede linkage, or render it more difficult. That does not mean that integrity and ambition should be neglected - indeed, experience with the CDM has shown that concerns about integrity shortcomings ultimately undermined the market for CDM offset credits. But such concerns are best addressed under the corresponding negotiating tracks, such as the "Talanoa Dialogue" to take stock of the collective efforts of Parties, or the enhanced transparency framework under Article 13 of the Paris Agreement. True to the spirit of the Paris Agreement, less may be more in this case, and definition of environmental and other standards may be best left to the regional, national and sub-national jurisdictions who choose to link.

If the combination of common accounting rules and an absence of restrictive criteria and conditions can accelerate linkage and allow for broader and deeper climate policy cooperation, it could also increase the latitude of Parties to scale up the ambition of their NDCs. And that may ultimately foster stronger engagement between Parties and non-Parties, as well as with regional and sub-national jurisdictions.

106 Wolfgang Obergassel \& Friederike Asche, Shaping the Paris Mechanisms Part III: An Update on Submissions on Article 6 of the Paris Agreement (JIKO Policy Paper No. 05/2017, Nov. 2017), https://perma.cc/9YES-RVYJ.

107 UNFCCC, Guidance on Cooperative Approaches Referred to in Article 6, Paragraph 2, of the Paris Agreement. Draft conclusions proposed by the Chair, FCCC/SBSTA/2017/L.26 (Nov. 14, 2017), https://perma.cc/SH589A3X.

108 Howard, supra note 66. 
Table 1: Existing Regional, National, and Sub-National Climate Policy Linkages

\begin{tabular}{|c|c|c|c|c|c|c|c|c|c|}
\hline \multirow[b]{2}{*}{ System 1} & \multirow[b]{2}{*}{ System 2} & \multirow{2}{*}{$\begin{array}{l}\text { Type of } \\
\text { Linkage }\end{array}$} & \multirow{2}{*}{$\begin{array}{l}\text { Enact. } \\
\text { Date }\end{array}$} & \multirow{2}{*}{$\begin{array}{l}\text { Effect. } \\
\text { Date }\end{array}$} & \multicolumn{2}{|c|}{ Prices at Enactment } & \multicolumn{2}{|c|}{ Caps $\left(\mathrm{mtCO}_{2}\right)$} & \multirow[b]{2}{*}{ Notes } \\
\hline & & & & & \#1 & \#2 & \#1 & \#2 & \\
\hline \multicolumn{10}{|c|}{ Linkages among cap-and-trade systems } \\
\hline 27 EU nations & (via the EU ETS) & Multi & 2003 & 2005 & none & na & varied & 2,299 & \\
\hline Norway & EU ETS & One-way & & 2005 & & & & & \\
\hline Norway & EU ETS & Multi & 2007 & 2008 & $€ 0$ & $€ 20$ & 15 & 2,080 & \\
\hline Iceland & EU ETS & Multi & 2007 & 2008 & none & $€ 20$ & 0 & 2,080 & G \\
\hline Liechtenstein & EU ETS & Multi & 2007 & 2008 & none & $€ 20$ & 18 & 2,080 & \\
\hline Switzerland & EU ETS & Two-way & & & & & & & \\
\hline Australia & EU ETS & One-way & $2013^{*}$ & 2014 & AUD\$25 & $€ 7-€ 8$ & TBD & & C \\
\hline Australia & EU ETS & Two-way & & 2018 & AUD\$25 & $€ 7-€ 8$ & TBD & 1,852 & \\
\hline Australia & New Zealand & Two-way & $*$ & & & & TBD & & \\
\hline Australia & EU ETS, NZ & Delinking & 2014 & 2014 & & & & & \\
\hline California & Quebec & Multi & $2012 / 13$ & 2014 & $\$ 14$ & none & 160 & 25 & 1 \\
\hline California & Ontario & Multi & 2017 & 2018 & $\$ 15$ & $\$ 15$ & 442 & 166 & I \\
\hline 10 U.S. states & (RGGI) & Multi & 2005 & 2009 & none & na & varied & 168 & A \\
\hline RGGI & Any CAT system & One-way & 2005 & 2009 & none & $€ 9 / E \cup A$ & 168 & 2,299 & B \\
\hline RGGI & Any CAT system & Delinking & 2013 & 2014 & $\$ 3$ & $€ 5 / E U A$ & 91 & 2,299 & B \\
\hline New Jersey & RGGI & Delinking & 2011 & 2012 & $\$ 2$ & $\$ 2$ & 21 & 150 & \\
\hline \multicolumn{10}{|c|}{ Linkages from cap-and-trade systems to credit systems } \\
\hline EU ETS Phase 1 & CDM & One-way & 2004 & 2005 & $€ 9$ & $\$ 5$ & 2,299 & na & $\mathrm{D}$ \\
\hline EU ETS Phase 2 & CDM & One-way & 2004 & 2008 & $€ 9$ & $\$ 5$ & 2,299 & na & $\mathrm{D}$ \\
\hline EU ETS Phase 3 & CDM & One-way & 2004 & 2013 & $€ 9$ & $\$ 5$ & 2,299 & na & $D, E$ \\
\hline EU ETS Phase 2 & 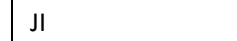 & One-way & 2004 & 2008 & $€ 9$ & $\$ 6$ & 2,299 & na & $\mathrm{D}$ \\
\hline EU ETS Phase 3 & Non-LDC CDM & Delinking & 2012 & 2013 & $€ 6$ & $€ 4$ & 2,084 & na & \\
\hline Switzerland & CDM & One-way & 1999 & 2008 & none & $\$ 4-\$ 7$ & na & na & \\
\hline New Zealand & CDM, JI, RMU & One-way & 2008 & 2008 & none & $€ 11$ & na & na & \\
\hline Australia & CDM, JI & One-way & 2011 & $2012 / 15$ & none & $€ 6$ & TBD & na & \\
\hline RGGI & Any credit system & One-way & 2005 & 2009 & none & $\$ 5-8$ & 110 & na & B \\
\hline RGGI & Any credit system & Delinking & 2013 & 2014 & none & $\$ 5$ & 165 & na & B \\
\hline California & Acre and Chiapas & One-way & & & & & & na & \\
\hline Quebec & Acre and Chiapas & One-way & ${ }^{*}$ & & & & & na & \\
\hline Tokyo ETS & CDM & One-way & 2008 & 2010 & $\$ 142$ & $\$ 18$ & 13 & na & $\mathrm{F}$ \\
\hline \multicolumn{10}{|c|}{ Linkage from carbon tax to credit systems } \\
\hline $\begin{array}{l}\text { Mexico } \\
\text { South Africa }\end{array}$ & \begin{tabular}{l|l}
$\mathrm{CDM}$ & \\
$\mathrm{CDM}, \mathrm{VCS}$
\end{tabular} & $\begin{array}{l}\text { One-Way } \\
\text { One-Way }\end{array}$ & $\begin{array}{l}2013 \\
2013\end{array}$ & $\begin{array}{l}2014 \\
\text { Delayed }\end{array}$ & none & $€ .4$ & na & na & $\mathrm{H}$ \\
\hline
\end{tabular}

*indicates a proposed linkage.

A The RGGI states signed a MOU in 2005, and then each passed authorizing legislation between 2006 and 2008.

${ }^{B}$ The original Model Rule included language (section XX-10.3(b)(1)) allowing the use of allowances from foreign cap-and-trade or credit systems (including Kyoto flexibility mechanisms) if RGGI allowance prices exceeded a "two-stage price trigger event" that began at $\$ 10$ in 2005 and increased by roughly 2 percent each year. The 2013 amendments to the Model Rule eliminated this linkage.

' Participants in Australia's system may use EUAs for up to 50 percent of their compliance obligations.

${ }^{D}$ Credit price reflects pre-compliance offsets for which seller assumes risk.

E Under recent proposed rules, EU ETS participants will be entitled to use international credits during the 2012-2020 period up to the higher of two limits: (a) the international credit entitlement specified in the national allocation plan for Phase 2; or (b) 11 percent of the free allocation of EU allowances granted to them in that period.

F Use of CDM credits is allowed only if domestic prices exceed a threshold, and if Tokyo-based credits are used as well.

${ }^{G}$ Per EEA Joint Committee decision 146/2007, Iceland did not submit a National Allocation Plan for EU ETS Phase II, since it had no installations large enough to be covered by the cap-and-trade system.

${ }^{H}$ Mexico allows companies to pay with CDM credits in lieu of tax payments equal to the credit market value at the time of paying the tax; however, only CDM projects developed in Mexico can be used in this way. The price shown in the table if from RGGI.

' Information on the cap at the time of linkage. California's cap expanded significantly in 2015 with the upstream inclusion of heating and transportation fuel emissions.

Source: Ranson et al., supra note 14, updated by authors. 
Table 2: Key Relevant Features of Submitted INDCs and NDCs

\begin{tabular}{|c|c|c|c|}
\hline Feature & Option Employed & $\begin{array}{c}\text { Number of } \\
\text { INDCs/NDC } \\
s \\
\end{array}$ & $\begin{array}{c}\text { Share of } \\
\text { Global } \\
\text { Emissions }\end{array}$ \\
\hline \multirow{4}{*}{ GHG Target Type } & Absolute GHG (mass-based) & 43 & $41 \%$ \\
\hline & GHG Relative to BAU & 74 & $16 \%$ \\
\hline & GHG Intensity (per unit of GDP) & 10 & $33 \%$ \\
\hline & Other \& No GHG Emissions Target & 36 & $6 \%$ \\
\hline \multirow{5}{*}{ Non-GHG Target Type } & Renewable Energy (only) & 63 & $13 \%$ \\
\hline & Energy Efficiency (only) & 1 & $0 \%$ \\
\hline & Forestry (only) & 10 & $2 \%$ \\
\hline & Multiple Non-GHG Targets & 63 & $13 \%$ \\
\hline & No Non-GHG Target & 72 & $49 \%$ \\
\hline \multirow[b]{3}{*}{ Conditionality } & Unconditional (only) & 34 & $68 \%$ \\
\hline & Conditional (only) & 49 & $12 \%$ \\
\hline & Combination & 80 & $16 \%$ \\
\hline \multirow[b]{3}{*}{ Base Year } & Historic Year or Fixed Level & 53 & $74 \%$ \\
\hline & Projected BAU Emissions & 79 & $16 \%$ \\
\hline & Not Specified & 31 & $6 \%$ \\
\hline \multirow{4}{*}{ Target Year } & Single Year (2030) & 106 & $70 \%$ \\
\hline & Singe Year (other year) & 11 & $20 \%$ \\
\hline & Multiple Years (2030 and at least one other year) & 11 & $1 \%$ \\
\hline & Not Specified & 35 & $6 \%$ \\
\hline \multirow{4}{*}{ Sectoral Coverage } & All Sectors & 71 & $86 \%$ \\
\hline & Energy plus 1-3 Other Sectors & 66 & $7 \%$ \\
\hline & Energy (only) & 20 & $1 \%$ \\
\hline & Some Energy Sub-Sectors (only) & 6 & $2 \%$ \\
\hline \multirow{4}{*}{ GHG Coverage } & All GHGs (using Kyoto Protocol definitions) & 39 & $57 \%$ \\
\hline & $\mathrm{CO}_{2}$ plus some others & 85 & $8 \%$ \\
\hline & $\mathrm{CO}_{2}$ (only) & 16 & $25 \%$ \\
\hline & Not Specified & 23 & $6 \%$ \\
\hline \multirow{4}{*}{$\begin{array}{c}\text { Global Warming } \\
\text { Potentials }\end{array}$} & IPCC AR2 & 45 & $5 \%$ \\
\hline & IPCC AR4 & 33 & $45 \%$ \\
\hline & IPCC AR5 & 3 & $4 \%$ \\
\hline & Not Specified & 82 & $42 \%$ \\
\hline
\end{tabular}

Source: GRAICHEN et al., supra note 74 (as of October 12, 2016). 
Table 3: Selected Key Features of G20 INDCs and NDCs

\begin{tabular}{|c|c|c|c|c|c|c|}
\hline Party & $\begin{array}{c}\text { Share of } \\
\text { Global } \\
\text { Emissio } \\
\text { ns }\end{array}$ & $\begin{array}{l}\text { GHG } \\
\text { Target }\end{array}$ & $\begin{array}{l}\text { Non-GHG } \\
\text { Targets }\end{array}$ & $\begin{array}{c}\text { Sectoral } \\
\text { Coverag } \\
\text { e }\end{array}$ & $\begin{array}{c}\text { GHG } \\
\text { Coverag } \\
\text { e }\end{array}$ & $\begin{array}{c}\text { Conditionali } \\
\text { ty }\end{array}$ \\
\hline Argentina & $1 \%$ & $\begin{array}{l}\text { Relative to } \\
\text { BAU }\end{array}$ & & $\begin{array}{c}\text { All } \\
\text { Sectors }\end{array}$ & All GHGs & $\begin{array}{c}\text { Combinatio } \\
n\end{array}$ \\
\hline Australia & $1 \%$ & Absolute GHG & $\begin{array}{l}\text { Renewable } \\
\text { Energy }\end{array}$ & $\begin{array}{c}\text { All } \\
\text { Sectors }\end{array}$ & All GHGs & $\begin{array}{c}\text { Uncondition } \\
\text { al }\end{array}$ \\
\hline Brazil & $2 \%$ & Absolute GHG & $\begin{array}{l}\text { Renewable } \\
\text { Energy }\end{array}$ & $\begin{array}{c}\text { All } \\
\text { Sectors }\end{array}$ & All GHGs & $\begin{array}{c}\begin{array}{c}\text { Uncondition } \\
\text { al }\end{array} \\
\end{array}$ \\
\hline Canada & $2 \%$ & Absolute GHG & & $\begin{array}{c}\text { All } \\
\text { Sectors }\end{array}$ & All GHGs & $\begin{array}{c}\text { Uncondition } \\
\text { al }\end{array}$ \\
\hline China & $25 \%$ & GHG Intensity & $\begin{array}{l}\text { Multiple Non- } \\
\text { GHG }\end{array}$ & $\begin{array}{c}\text { All } \\
\text { Sectors }\end{array}$ & $\mathrm{CO}_{2}$ & $\begin{array}{c}\text { Uncondition } \\
\text { al }\end{array}$ \\
\hline $\begin{array}{l}\text { European } \\
\text { Union }\end{array}$ & $11 \%$ & Absolute GHG & & $\begin{array}{c}\text { All } \\
\text { Sectors }\end{array}$ & All GHGs & $\begin{array}{c}\text { Uncondition } \\
\text { al }\end{array}$ \\
\hline India & $7 \%$ & GHG Intensity & $\begin{array}{l}\text { Multiple Non- } \\
\text { GHG }\end{array}$ & $\begin{array}{c}\text { All } \\
\text { Sectors }\end{array}$ & All GHGs & Conditional \\
\hline Indonesia & $2 \%$ & $\begin{array}{l}\text { Relative to } \\
\text { BAU }\end{array}$ & $\begin{array}{l}\text { Renewable } \\
\text { Energy }\end{array}$ & $\begin{array}{c}\text { All } \\
\text { Sectors }\end{array}$ & $\mathrm{CO}_{2}$, etc. & $\begin{array}{c}\text { Combinatio } \\
n\end{array}$ \\
\hline Japan & $3 \%$ & Absolute GHG & $\begin{array}{l}\text { Renewable } \\
\text { Energy }\end{array}$ & $\begin{array}{c}\text { All } \\
\text { Sectors }\end{array}$ & All GHGs & $\begin{array}{c}\begin{array}{c}\text { Uncondition } \\
\text { al }\end{array} \\
\text {. }\end{array}$ \\
\hline $\begin{array}{l}\text { South } \\
\text { Korea }\end{array}$ & $1 \%$ & $\begin{array}{l}\text { Relative to } \\
\text { BAU }\end{array}$ & & $\begin{array}{l}\text { (No } \\
\text { LUCF) }\end{array}$ & All GHGs & $\begin{array}{c}\text { Uncondition } \\
\text { al }\end{array}$ \\
\hline Mexico & $1 \%$ & $\begin{array}{l}\text { Relative to } \\
\text { BAU }\end{array}$ & & $\begin{array}{c}\text { All } \\
\text { Sectors }\end{array}$ & All GHGs & $\begin{array}{c}\text { Combinatio } \\
n\end{array}$ \\
\hline $\begin{array}{l}\text { Russian } \\
\text { Federation }\end{array}$ & $5 \%$ & Absolute GHG & & $\begin{array}{c}\text { All } \\
\text { Sectors }\end{array}$ & All GHGs & $\begin{array}{c}\text { Uncondition } \\
\text { al }\end{array}$ \\
\hline $\begin{array}{l}\text { Saudi } \\
\text { Arabia }\end{array}$ & $1 \%$ & & Actions Only & $\begin{array}{l}\text { Energy } \\
\text { Sub-Sec }\end{array}$ & $\begin{array}{c}\text { Not } \\
\text { Specifie } \\
d \\
\end{array}$ & Conditional \\
\hline $\begin{array}{l}\text { South } \\
\text { Africa }\end{array}$ & $1 \%$ & GHG Peaks & & $\begin{array}{c}\text { All } \\
\text { Sectors }\end{array}$ & All GHGs & $\begin{array}{c}\text { Combinatio } \\
\mathrm{n}\end{array}$ \\
\hline Turkey & $1 \%$ & $\begin{array}{l}\text { Relative to } \\
\text { BAU }\end{array}$ & $\begin{array}{l}\text { Renewable } \\
\text { Energy }\end{array}$ & $\begin{array}{c}\text { All } \\
\text { Sectors }\end{array}$ & All GHGs & $\begin{array}{c}\text { Combinatio } \\
\mathrm{n}\end{array}$ \\
\hline $\begin{array}{l}\text { United } \\
\text { States }\end{array}$ & $15 \%$ & Absolute GHG & & $\begin{array}{c}\text { All } \\
\text { Sectors }\end{array}$ & All GHGs & $\begin{array}{c}\text { Uncondition } \\
\text { al }\end{array}$ \\
\hline
\end{tabular}

Source: GRAICHEN et al., supra note 74 (as of October 12, 2016). 
Table 4: Five Cases of Potential Linkages for Five Categories of Heterogeneity

\begin{tabular}{|c|c|c|c|c|c|}
\hline \multirow{3}{*}{ Case } & \multicolumn{5}{|c|}{ Categories of Heterogeneity } \\
\hline & \multirow{2}{*}{ Policy Instrument } & \multicolumn{2}{|c|}{ Jurisdiction/Scope } & \multicolumn{2}{|c|}{ Target } \\
\hline & & $\begin{array}{c}\text { Level } \\
\text { of Jurisdiction }\end{array}$ & $\begin{array}{c}\text { Status under } \\
\text { Paris } \\
\text { Agreement }\end{array}$ & $\begin{array}{c}\text { Policy } \\
\text { Instrument }\end{array}$ & NDC \\
\hline 1 & $\begin{array}{c}\text { Cap-and-Trade } \\
+ \\
\text { Cap-and-Trade }\end{array}$ & $\begin{array}{c}\text { National } \\
+ \\
\text { National }\end{array}$ & $\begin{array}{l}\text { Party } \\
+ \\
\text { Party }\end{array}$ & $\begin{array}{c}\text { Mass-Based } \\
+ \\
\text { Mass-Based }\end{array}$ & $\begin{array}{c}\text { Absolute GHG } \\
+ \\
\text { Absolute GHG }\end{array}$ \\
\hline 2 & $\begin{array}{c}\text { Carbon Tax } \\
+ \\
\text { Cap-and-Trade }\end{array}$ & $\begin{array}{c}\text { Sub-National } \\
+ \\
\text { Sub-National }\end{array}$ & $\begin{array}{c}\text { In a Party } \\
+ \\
\text { in a Party }\end{array}$ & $\begin{array}{c}\text { Mass-Based } \\
+ \\
\text { Mass-Based }\end{array}$ & $\begin{array}{l}\text { Absolute GHG } \\
+ \\
\text { Absolute GHG }\end{array}$ \\
\hline 3 & $\begin{array}{c}\text { Cap-and-Trade } \\
+ \\
\text { Cap-and-Trade }\end{array}$ & $\begin{array}{c}\text { Regional } \\
+ \\
\text { Sub-National }\end{array}$ & $\begin{array}{c}\text { Party } \\
+ \\
\text { in a Non-Party }\end{array}$ & $\begin{array}{c}\text { Mass-Based } \\
+ \\
\text { Mass-Based }\end{array}$ & $\begin{array}{c}\text { Absolute GHG } \\
+ \\
\text { N/A }\end{array}$ \\
\hline 4 & $\begin{array}{c}\text { Performance Standard } \\
+ \\
\text { Cap-and-Trade }\end{array}$ & $\begin{array}{c}\text { National } \\
+ \\
\text { National }\end{array}$ & $\begin{array}{l}\text { Party } \\
+ \\
\text { Party }\end{array}$ & $\begin{array}{c}\text { Rate-Based } \\
+ \\
\text { Mass-Based }\end{array}$ & $\begin{array}{c}\text { Absolute GHG } \\
+ \\
\text { Relative GHG }\end{array}$ \\
\hline 5 & $\begin{array}{c}\text { Carbon Tax } \\
+ \\
\text { Carbon Tax }\end{array}$ & $\begin{array}{c}\text { National } \\
+ \\
\text { National }\end{array}$ & $\begin{array}{c}\text { Non-Party } \\
+ \\
\text { Non-Party }\end{array}$ & $\begin{array}{c}\text { Mass-Based } \\
+ \\
\text { Mass-Based }\end{array}$ & N/A \\
\hline
\end{tabular}




\section{Appendix 1: Paris Agreement Article 6}

1. Parties recognize that some Parties choose to pursue voluntary cooperation in the implementation of their nationally determined contributions to allow for higher ambition in their mitigation and adaptation actions and to promote sustainable development and environmental integrity.

2. Parties shall, where engaging on a voluntary basis in cooperative approaches that involve the use of internationally transferred mitigation outcomes towards nationally determined contributions, promote sustainable development and ensure environmental integrity and transparency, including in governance, and shall apply robust accounting to ensure, inter alia, the avoidance of double counting, consistent with guidance adopted by the Conference of the Parties serving as the meeting of the Parties to this Agreement.

3. The use of internationally transferred mitigation outcomes to achieve nationally determined contributions under this Agreement shall be voluntary and authorized by participating Parties.

4. A mechanism to contribute to the mitigation of greenhouse gas emissions and support sustainable development is hereby established under the authority and guidance of the Conference of the Parties serving as the meeting of the Parties to this Agreement for use by Parties on a voluntary basis. It shall be supervised by a body designated by the Conference of the Parties serving as the meeting of the Parties to this Agreement, and shall aim:

(a) To promote the mitigation of greenhouse gas emissions while fostering sustainable development;

(b) To incentivize and facilitate participation in the mitigation of greenhouse gas emissions by public and private entities authorized by a Party;

(c) To contribute to the reduction of emission levels in the host Party, which will benefit from mitigation activities resulting in emission reductions that can also be used by another Party to fulfil its nationally determined contribution; and

(d) To deliver an overall mitigation in global emissions.

5. Emission reductions resulting from the mechanism referred to in paragraph 4 of this Article shall not be used to demonstrate achievement of the host Party's nationally determined contribution if used by another Party to demonstrate achievement of its nationally determined contribution.

6. The Conference of the Parties serving as the meeting of the Parties to this Agreement shall ensure that a share of the proceeds from activities under the mechanism referred to in paragraph 4 of this Article is used to cover administrative expenses as well as to assist developing country Parties that are particularly vulnerable to the adverse effects of climate change to meet the costs of adaptation.

7. The Conference of the Parties serving as the meeting of the Parties to this Agreement shall adopt rules, modalities and procedures for the mechanism referred to in paragraph 4 of this Article at its first session.

8. Parties recognize the importance of integrated, holistic and balanced non-market approaches being available to Parties to assist in the implementation of their nationally determined contributions, in the context of sustainable development and poverty eradication, in a coordinated and effective manner, including through, inter alia, mitigation, adaptation, finance, technology transfer and capacity-building, as appropriate. These approaches shall aim to:

(a) Promote mitigation and adaptation ambition;

(b) Enhance public and private sector participation in the implementation of nationally determined contributions; and

(c) Enable opportunities for coordination across instruments and relevant institutional arrangements.

9. A framework for non-market approaches to sustainable development is hereby defined to promote the nonmarket approaches referred to in paragraph 8 of this Article. 
A necessary condition for globally cost effective policy is that the marginal cost of abatement be equalized across sources of emissions. The figure below, adapted from Metcalf and Weisbach (2010), illustrates the gains from satisfying this condition. The box has width equal to $\mathrm{Q}^{\text {Total }}$, the total amount of emissions to be reduced. We measure emissions reductions by country A starting at the lower left corner of the box, with increasing abatement occurring as we move to the right. The upward sloping line denoted $\mathrm{MAC}_{\mathrm{A}}$ is the marginal abatement cost function for country A. It is upward sloping to reflect the fact that reducing emissions is increasingly costly as abatement rises. Emission reductions by country B are measured from the bottom right corner, with increasing abatement as we move to the left. Country B's marginal abatement cost curve starts at the lower right corner of the box and increases as we move to the left, but is less steep that that of country A. Thus, Country A is the high-cost controller in this example.

The figure illustrates a policy agreement where each country agrees to reduce emissions by the same amount. The marginal abatement cost for country $\mathrm{A}$ is higher than the marginal abatement cost for country $B$ at the point where $\mathrm{Q}_{\mathrm{A}}$ equals $\mathrm{Q}_{\mathrm{B}}$. If abatement activity were to shift one unit of emissions from country B to country A (shift one unit of emissions abatement from country A to B), the savings in aggregate abatement costs would equal the vertical distance between the two marginal abatement cost curves. If abatement responsibilities were shifted from country A to country B until the marginal abatement costs were equalized across the two countries, we would achieve reductions in aggregate abatement costs equal to the area of the shaded triangle in the figure, labeled $\mathrm{C}_{2}$. Once marginal abatement costs are equalized, no opportunities exist for further reductions in abatement costs by reallocating abatement activity between the two countries.

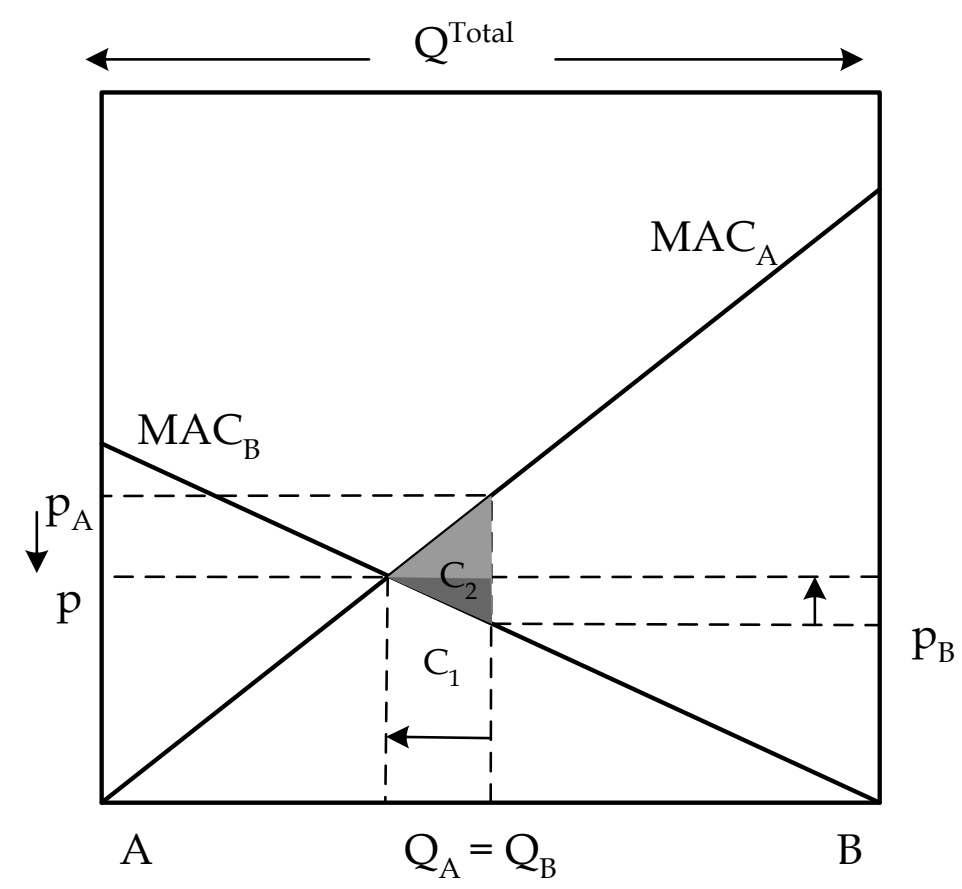

